\title{
Open Rotor Tone Shielding Methods for System Noise Assessments Using Multiple Databases
}

\author{
Christopher J. Bahr* Russell H. Thomas† Leonard V. Lopesł Casey L. Burley ${ }^{\S}$ \\ NASA Langley Research Center, Hampton, VA 23681 \\ and \\ Dale E. Van Zante \\ NASA Glenn Research Center, Cleveland, OH 44135
}

\begin{abstract}
Advanced aircraft designs such as the hybrid wing body, in conjunction with open rotor engines, may allow for significant improvements in the environmental impact of aviation. System noise assessments allow for the prediction of the aircraft noise of such designs while they are still in the conceptual phase. Due to significant requirements of computational methods, these predictions still rely on experimental data to account for the interaction of the open rotor tones with the hybrid wing body airframe. Recently, multiple aircraft system noise assessments have been conducted for hybrid wing body designs with open rotor engines. These assessments utilized measured benchmark data from a Propulsion Airframe Aeroacoustic interaction effects test. The measured data demonstrated airframe shielding of open rotor tonal and broadband noise with legacy F7/A7 open rotor blades. Two methods are proposed for improving the use of these data on general open rotor designs in a system noise assessment. The first, direct difference, is a simple octave band subtraction which does not account for tone distribution within the rotor acoustic signal. The second, tone matching, is a higher-fidelity process incorporating additional physical aspects of the problem, where isolated rotor tones are matched by their directivity to determine tone-by-tone shielding. A case study is conducted with the two methods to assess how well each reproduces the measured data and identify the merits of each. Both methods perform similarly for system level results and successfully approach the experimental data for the case study. The tone matching method provides additional tools for assessing the quality of the match to the data set. Additionally, a potential path to improve the tone matching method is provided.
\end{abstract}

\section{Nomenclature}

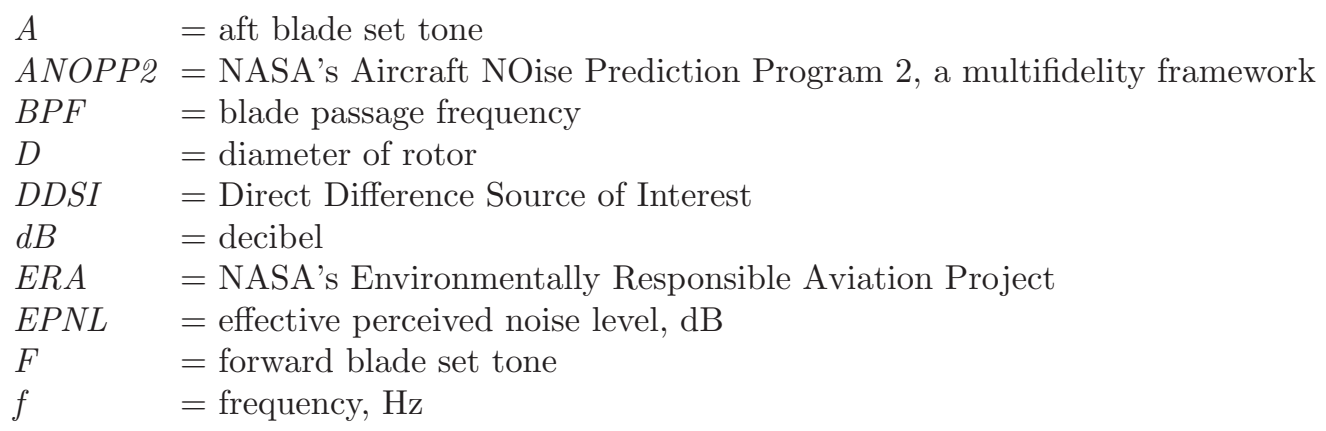

*Research Aerospace Engineer, Aeroacoustics Branch, MS 461, Member AIAA, christopher.j.bahr@nasa.gov

${ }^{\dagger}$ Senior Research Engineer, Aeroacoustics Branch, MS 461, Senior Member AIAA

${ }^{\ddagger}$ Research Aerospace Engineer, Aeroacoustics Branch, MS 461, Member AIAA

$\S$ Senior Research Engineer, Aeroacoustics Branch, MS 461, Senior Member AIAA

『Aerospace Engineer, Acoustics Branch, MS 54-3, Senior Member AIAA 


$\begin{array}{ll}H W B & =\text { Hybrid Wing Body } \\ I R S & =\text { Isolated Reference Source } \\ I S I & =\text { Isolated Source of Interest } \\ \text { LSAF } & =\text { Low Speed Aeroacoustic Facility, Boeing } \\ N+2 & =\text { NASA terminology for aircraft technology entering service in } 2025 \\ \text { OREIO } & =\text { Boeing designed Open Rotor Engine Integration on an HWB } \\ P A A & =\text { Propulsion Airframe Aeroacoustics } \\ P N L T & =\text { tone-corrected perceived noise level, dB } \\ R P M & =\text { revolutions per minute } \\ R S S & =\text { Reference Source Shielding } \\ S P L & =\text { sound pressure level, dB } \\ S R S & =\text { Shielded Reference Source } \\ S S I & =\text { Shielded Source of Interest } \\ T M S I & =\text { Tone-Matched Source of Interest } \\ x & =\text { rotor location ahead of model trailing edge } \\ \Delta d B & =\text { sound pressure level difference between shielded and unshielded } \\ \theta & =\text { polar directivity angle (downstream axis at } 180 \text { degrees), degrees } \\ \psi & =\text { azimuthal directivity angle, degrees }\end{array}$

\section{Introduction}

ETERmining the positive environmental impact of advanced aircraft concepts is both the motivation

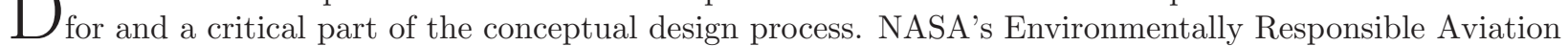
(ERA) Project ${ }^{1}$ has been focusing on its N+2 goals, including a fuel burn reduction of $50 \%$ relative to the 2005 best-in-class baseline, an emissions reduction of $75 \%$ NOx below the Committee on Aviation Environmental Protection (CAEP) 6 standard, and a noise reduction of $42 \mathrm{~dB}$ cumulative effective perceived noise level (EPNL) relative to the Stage 4 requirement. These goals have spurred studies of concept aircraft with propulsion systems that are considered radically different than those currently in use. One particular design of interest is the Hybrid Wing Body (HWB) with the propulsion system mounted above the aircraft airframe. ${ }^{2}$ The HWB airframe design provides shielding to ground-based observers from the noise generated by a topmounted propulsion system. One aircraft concept that incorporates airframe shielding with an open rotor propulsion system is the Boeing Open Rotor Engine Integration on an HWB (OREIO), shown in Fig. $1 .^{3}$ Such a design leverages the fuel burn advantages of open $\operatorname{rotors}^{4-6}$ and the noise shielding of the HWB, offering a potential vehicle that meets the ERA N+2 goals.

System noise assessment is a process for determining the potential community noise impact of an aircraft design. $^{7-9}$ The assessment process accounts for the potential noise sources on an aircraft during takeoff and landing for each of three certification conditions: Approach, Sideline, and Cutback. In evaluating the OREIO design, the rotor and airframe noise sources are both significant, as are the effects of Propulsion Airframe Aeroacoustic (PAA) interactions. Among these interactions is shielding, which is a primary acoustic advantage inherent in this concept. Deploying computational prediction methods is not yet realistic for noise assessments at the aircraft conceptual level due to the lack of definition of the aircraft configuration and the time required for high fidelity computations. This is certainly the case for the PAA effects of open rotors. The noise assessment process at the conceptual design stage must provide sufficient accuracy to guide the design towards quiet configurations and at the same time be relatively fast to accommodate design changes. However, the fidelity and accuracy of the noise assessment is directly a function of methods and data used. Interpretation of the results subsequently depends on the fidelity and accuracy. Since at the conceptual design stage the details of the design are not exactly known, the noise prediction requires careful use of the available information to obtain the highest fidelity results with confidence.

In recent studies of advanced aircraft, noise was assessed using aircraft noise prediction processes that employ both measured data as well as predictive methods. ${ }^{8}$ High quality experimental data must be used in the best possible way within the system noise prediction process. A recent example of this is the extensive database acquired for the PAA interactions of an open rotor with multiple airframes, including an HWB. ${ }^{10}$ This experiment was conducted using an open rotor model with the F7/A7 blade design. The data set includes a large number of HWB configurations that vary rotor location, elevon deflection, and vertical tail 
configurations as well as advanced noise reduction concepts such as exterior airframe liners. These results have been used to characterize the acoustic benefits that can be expected for various configurations of an HWB. ${ }^{11}$ The unique noise character of the open rotor is due to the complex tones from its counter-rotating forward and aft rotors. The scattered noise field due to the presence of the body is a function of the frequency, and thus wavelength of the tones and their directivity. As mentioned by Guo et al., ${ }^{11}$ the unique tonal and directivity features of the installed open rotor noise field must be considered when utilizing the results within a noise assessment. Representing the installed open rotor characterization in terms of shielding suppression maps, which show the change in a rotor acoustic field from an isolated rotor experiment to a shielded rotor experiment, provides a means by which these effects can be used to account for installation of open rotor designs on an HWB. The availability of this data has enabled higher fidelity studies of advanced concepts where open rotor engines are installed above an aircraft shielding structure to reduce community noise. ${ }^{12}$

A system noise assessment of the OREIO HWB has been conducted using the ANOPP2 framework, ${ }^{7}$ and is presented in a companion paper. ${ }^{13}$ The intent of that assessment is to determine the potential noise reduction benefits of a modern open rotor design installed on the OREIO HWB aircraft as shown in Fig. 1a. The shielding data are incorporated using the suppression maps constructed from the LSAF PAA test data. A suppression map is constructed for a given configuration by simulating or measuring the levels and directivity of an isolated open rotor, and then the levels and directivity of a shielded open rotor, for a given flight condition. The difference between these two, in $\mathrm{dB}$ and with appropriate run-to-run corrections accounting for changes in experimental conditions can be used to model how a given source is suppressed by a shielding body at a given observer location.

In this paper, the methodology for constructing shielding suppression maps from the comprehensive LSAF PAA noise database is presented. Two methodologies for applying the suppression maps to alternate rotor designs are presented along with associated issues. One is called the direct difference method, and the other the tone matching method. Both are used to enable the system noise assessment of the OREIO HWB in Thomas et al. ${ }^{13}$

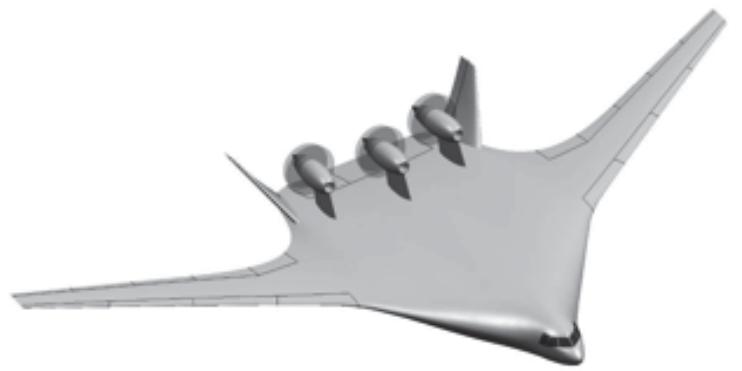

(a) OREIO Hybrid Wing Body aircraft concept with open rotor propulsion system (image credit Boeing ${ }^{3}$ ).

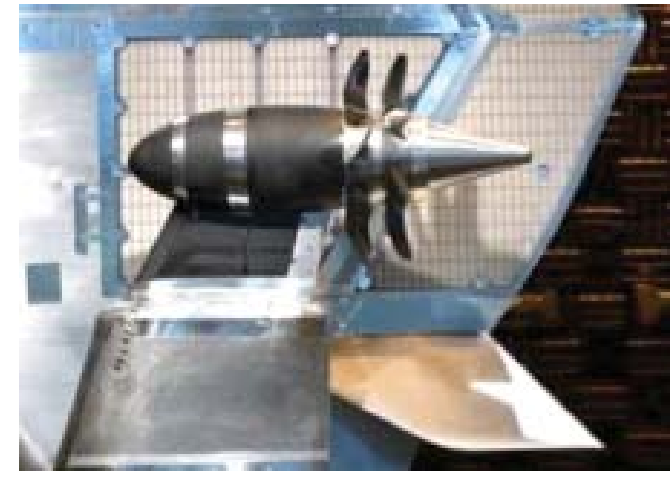

(b) Example F7/A7 open rotor installation with a hybrid wing body airframe from LSAF PAA experiments. ${ }^{10}$

Figure 1. Concept and experimental installations of open rotors with hybrid wing body aircraft designs.

\section{Suppression Maps with Tone Measurements}

A suppression map is a representation of the effect of a given installation on an isolated source's directivity. The construction of a suppression map is, in principle, a straightforward procedure. Data are acquired for an isolated source configuration as a function of frequency and directivity, for example an open rotor installation in a wind tunnel. The acquisition is then repeated for the same positions, locations, and conditions, but with a shielding airframe of interest, thus providing a shielded source measurement. Suppression is defined as the difference between shielded to unshielded acoustic fields, given by

$$
\Delta \mathrm{dB}(f, \theta, \psi)=\operatorname{SPL}(f, \theta, \psi)_{\text {shielded }}-\operatorname{SPL}(f, \theta, \psi)_{\text {unshielded }} .
$$

Using the definition given in Eq. (1), $\Delta \mathrm{dB}<0$ indicates suppression and $\Delta \mathrm{dB}>0$ indicates amplification. Suppression may come from line-of-sight blockage of the shielding body or cancellations from coherent air- 


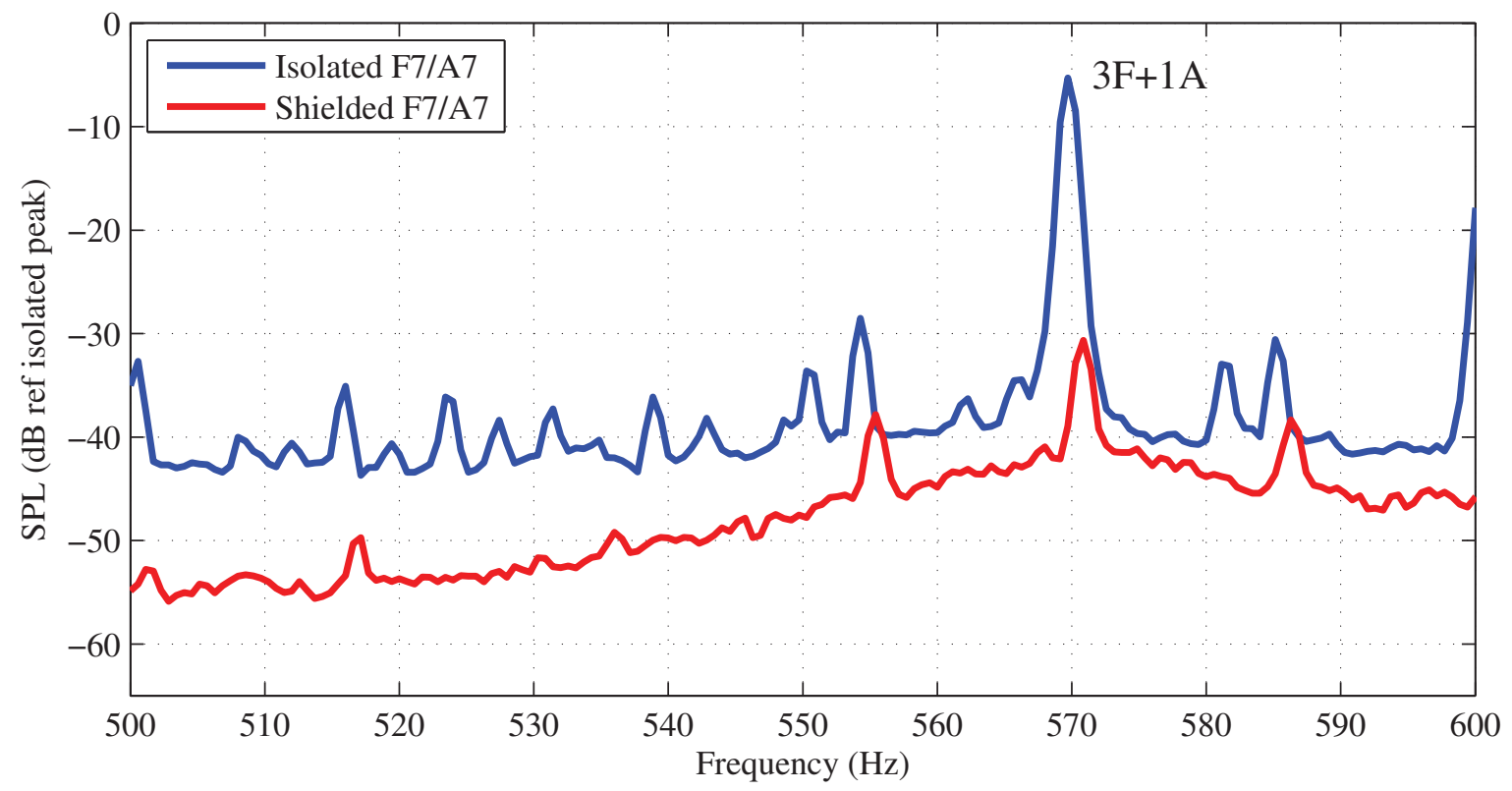

Figure 2. Example of the effect of model shielding and wake on F7/A7 tones from the LSAF PAA data set, 10 with the shielded rotor $x / D=1.0$ and no additional configuration features. Note that the peak reference in the $\mathrm{dB}$ scaling is the peak narrowband value of the full isolated spectrum, and not the local peak.

frame scattered fields. Amplification may come from summation of airframe incoherent or coherent scattered fields. Historically, $\Delta \mathrm{dB}$ is calculated on a $1 / 3^{\text {rd }}$ octave band basis for use with system noise assessment. However, the need for narrowband analysis will be discussed subsequently.

No matter how well controlled an experiment is, there will be slight rotor blade passage frequency changes from run to run. These frequency changes are exacerbated for higher blade harmonics. This is illustrated in Fig. 2, where the $3 \mathrm{~F}+1 \mathrm{~A}$ tone (interaction between the second harmonic of the forward rotor BPF and the fundamental aft rotor BPF) is shown for an example configuration from the LSAF PAA data. These data are normalized by the spectral peak of the isolated configuration in the $\mathrm{dB}$ calculation (which lies outside of this frequency range and is thus not shown). The spectra are scaled to full-scale frequency based on the ratio of diameters of the $\mathrm{F} 7 / \mathrm{A} 7$ rotor $(1 \mathrm{ft})$ to the OREIO rotor $(14 \mathrm{ft})$. The $3 \mathrm{~F}+1 \mathrm{~A}$ tone peak shifts approximately $2 \mathrm{~Hz}$ in frequency due to run-to-run differences in the forward and aft rotor BPFs. This shift is generally small for lower harmonics and interactions, but grows as a function of frequency.

Second, the tones experience a haystacking effect. As a tone passes through a shear layer, it will broaden in the frequency domain. ${ }^{14}$ A tone with a sharp peak prior to this effect may appear as a broad hump, or "haystack," once it has passed through the shear layer. Any tone from a rotor mounted on the top of an HWB will pass through the body's wake in transit to a ground-based observer. While the LSAF PAA data were acquired with in-flow microphones, avoiding the haystacking effect of the facility shear layer, the data still contain haystacking due to the wake of the model. In the case of the $3 \mathrm{~F}+1 \mathrm{~A}$ tone in Fig. 2 , the broad hump on which the shielded $3 \mathrm{~F}+1 \mathrm{~A}$ and adjacent tones reside appears to be due to the haystacking of these tones. These shielded tones have passed through the model wake, which is not present in the acquisition of the isolated tones.

\section{Suppression Map Construction \& Application}

Because the tones are not aligned, it is not correct to perform a direct narrowband subtraction in the calculation of $\Delta \mathrm{dB}$. The boxed region of the flowchart in Fig. 3 shows the process used in this study for constructing a suppression map. Tones must be identified, their widths computed, respective powers determined and frequencies aligned between the isolated and shielded data sets. The shielding effect on each of the tones is computed. The non-tonal frequency content of the spectrum is used to determine broadband shielding. These two shielding calculations are used to construct a synthetic shielded source. This synthetic 


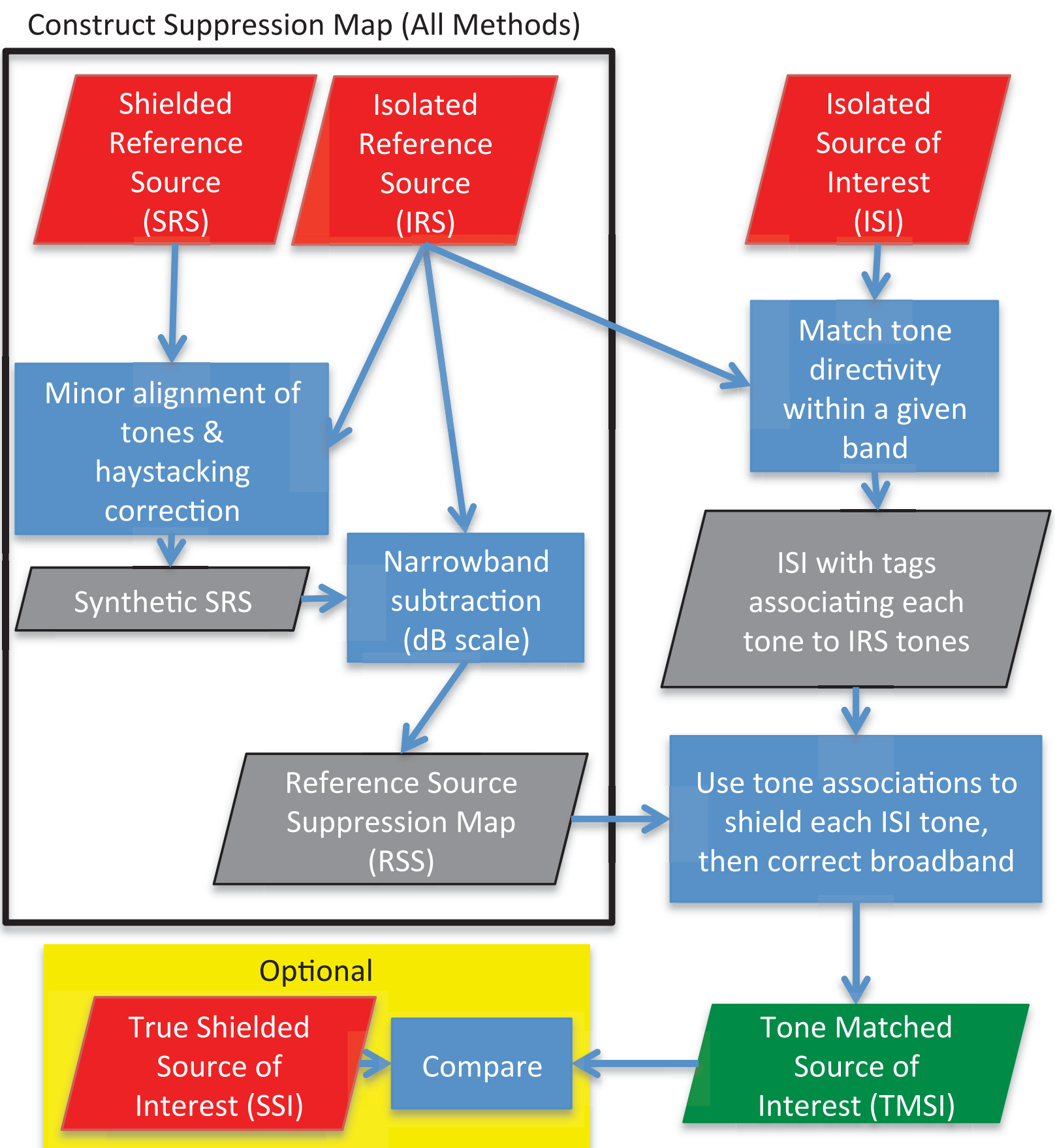

Figure 3. Data flow for the analysis in this research. Here, red parallelograms denote experimental data, gray parallelograms processed data, and blue rectangles a process. The procedure enclosed in the black box is followed for all methodologies, with the output of a suppression map. The surrounding procedure outlines the tone matching method to match suppression maps from one data set (IRS/SRS) to another data set (ISI). 


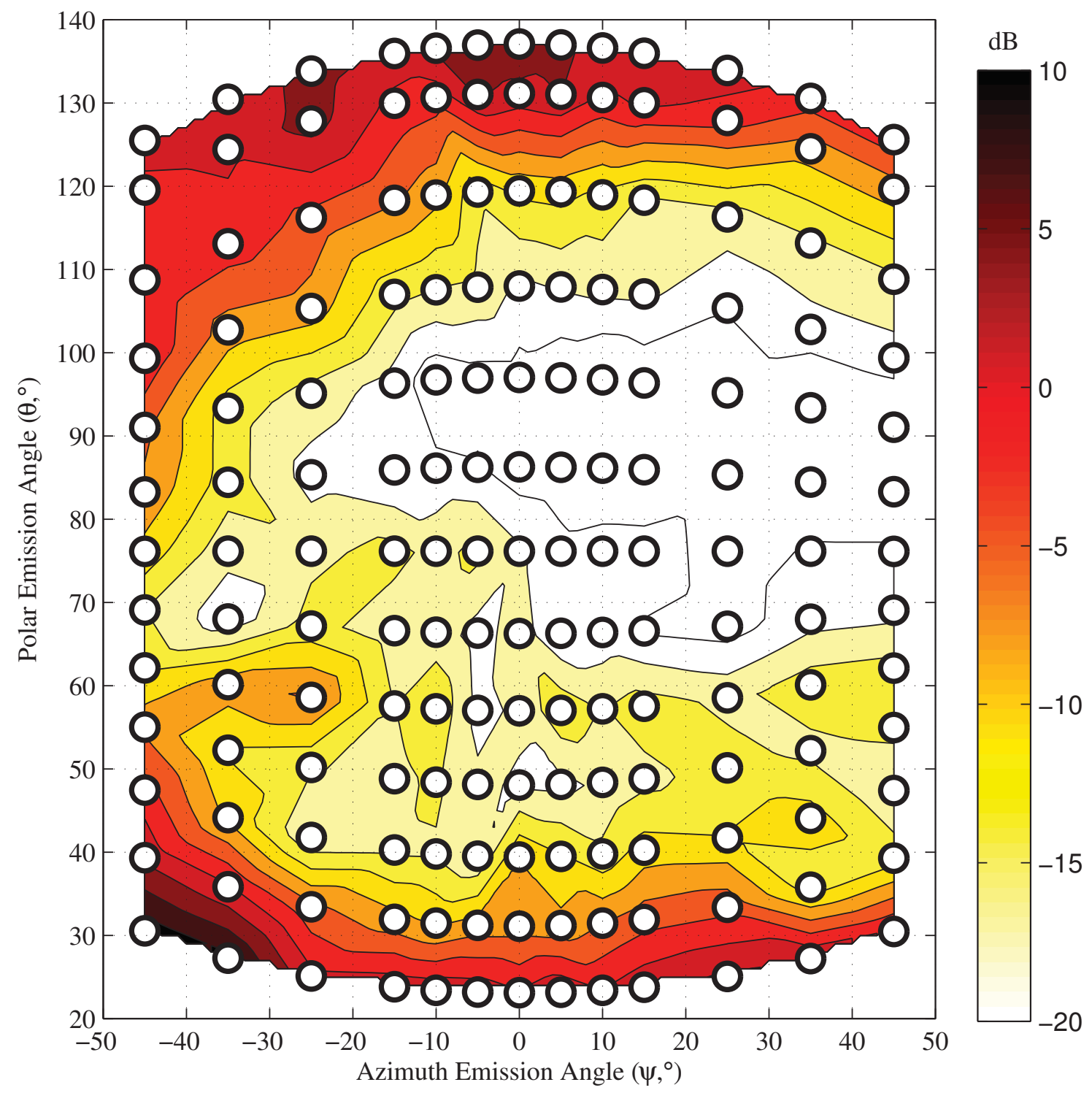

Figure 4. Example suppression map $(\Delta \mathrm{dB})$ of the $3 \mathrm{~F}+1 \mathrm{~A}$ tone from Fig. 2. Contour levels are every $3 \mathrm{~dB}$, with values above $10 \mathrm{~dB}$ truncated to $10 \mathrm{~dB}$ and values below $-20 \mathrm{~dB}$ plotted as white. Actual measurement locations are shown as black circles with white fill. The angular coordinates follow an aircraft flying downward on the page (nose pointing at $\theta=0^{\circ}$ ), with the port wing in the negative azimuth direction. Angle centers are referenced to the rotor center, between the forward and aft blade sets. Asymmetry is expected, as the installation is offset from the airframe centerline as shown in Fig. 1b. 
source can be used in direct, frequency-by-frequency subtraction with the isolated source to construct a suppression map.

An example suppression map for the $3 \mathrm{~F}+1 \mathrm{~A}$ tone in the example from Fig. 2 is shown in Fig. 4. Note that data are linearly-interpolated for plotting purposes. Actual measurement locations are marked in the figure as black circles with white fill. This suppression map shows that for the majority of the observed tone directivity, the tone experiences strong suppression. However, near the edges of the measurement region, the tone undergoes amplification. This suppression map is used for any system analysis which requires applying an airframe configuration or source change to an isolated source measurement.

The shielding data and configurations available from the LSAF PAA experiment are substantial. Developing methods to apply the suppression maps from the LSAF PAA data to arbitrary rotor designs enables advanced vehicle concept design. There are many factors to consider when developing such methods. For example, when open rotor designs change, the directivity of tones may change. The frequency of individual tones may also change, altering the wavelength-to-body scaling of individual tones and thus changing their scattering characteristics. Relationships between forward and aft BPFs and their interactions can shift. The relative strengths of individual tones and broadband levels can vary. An example of these changes is shown in Fig. 5, where F7/A7 blade set data from $\mathrm{LSAF}^{10}$ are compared to F31/A31 blade set data from NASA Glenn,${ }^{15}$ normalized to respective peak spectral levels and scaled to full-scale OREIO vehicle frequency as a function of rotor diameter, $D$. Here, all of the previously mentioned changes are observed, providing some challenges in matching data sets.

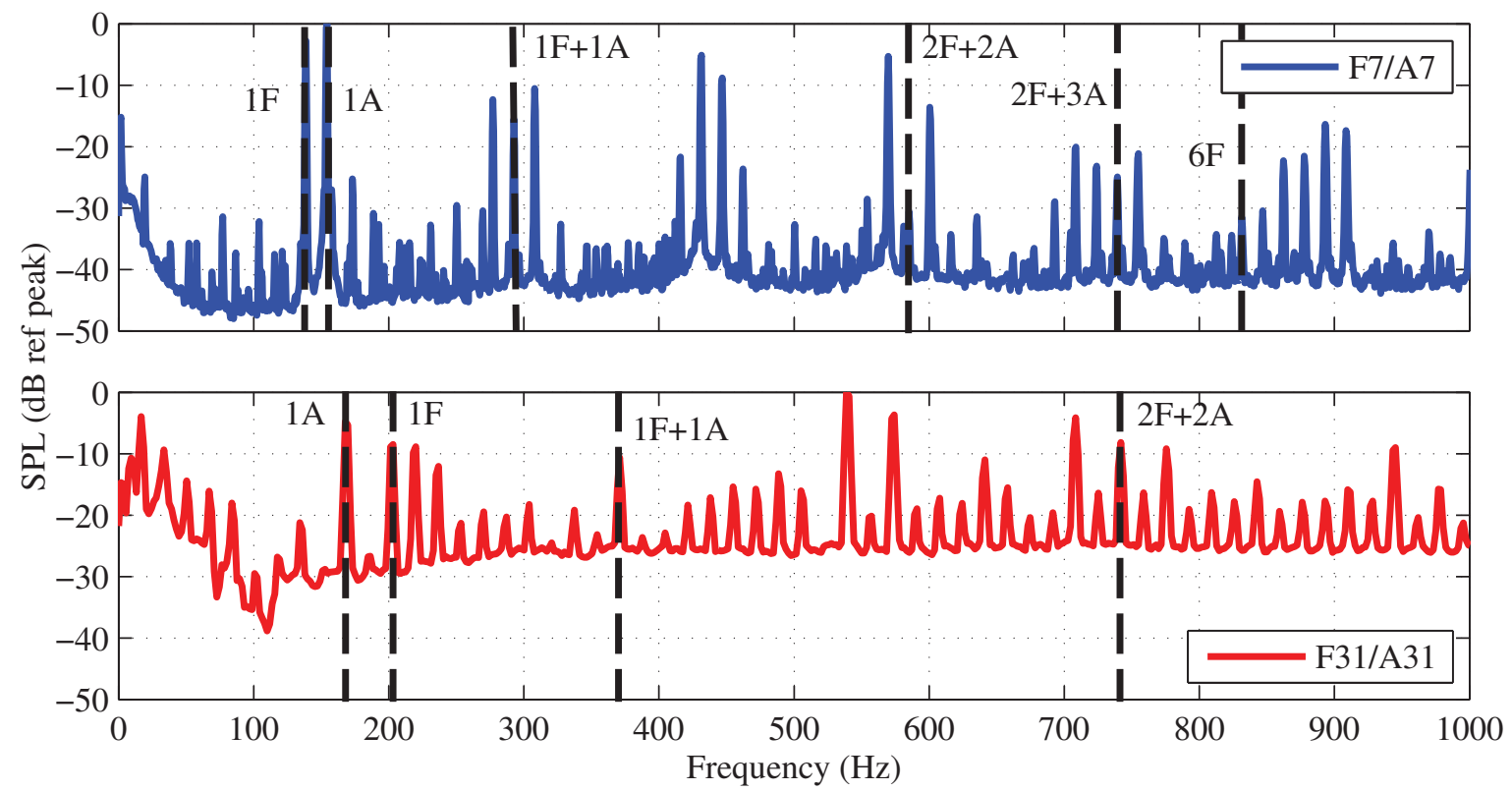

Figure 5. Comparison of normalized, full-scale spectra for different open rotor blade sets, as seen by an observer at $(\theta, \psi)=\left(90^{\circ}, 0^{\circ}\right)$.

From Fig. 5, it is evident that mapping a tone from one data set to the tone nearest in frequency in the other data set would result in, for example, the $2 \mathrm{~F}+2 \mathrm{~A}$ tone of the F31/A31 blade set mapping to a different tone (in this case the $2 \mathrm{~F}+3 \mathrm{~A}$ ) than the $2 \mathrm{~F}+2 \mathrm{~A}$ tone of the $\mathrm{F} 7 / \mathrm{A} 7$ blade set. This is illustrated in Fig. 6 , where the $\psi=0^{\circ}$ polar directivity of the $2 \mathrm{~F}+2 \mathrm{~A} \mathrm{~F} 31 / \mathrm{A} 31$ tone is compared to two $\mathrm{F} 7 / \mathrm{A} 7$ tones which have similar full-scale frequencies. However, a harmonic-for-harmonic tone substitution of the shielding information from the F7/A7 2F+2A tone to the F31/A31 2F+2A tone may not make physical sense, as the directivity of the $2 \mathrm{~F}+2 \mathrm{~A}$ F31/A31 tone differs significantly from the directivity of the $2 \mathrm{~F}+2 \mathrm{~A} \mathrm{~F} 7 / \mathrm{A} 7$ tone. Additionally, the frequencies, and thus wavelengths, of the respective $2 \mathrm{~F}+2 \mathrm{~A}$ tones are different, potentially causing the shielding effect of the HWB to change. Two methods designed to handle the challenge of matching data sets such as these are presented. Both balance trade-offs between maintaining the frequency content of the data sets and maintaining the directivity of the measurements. 


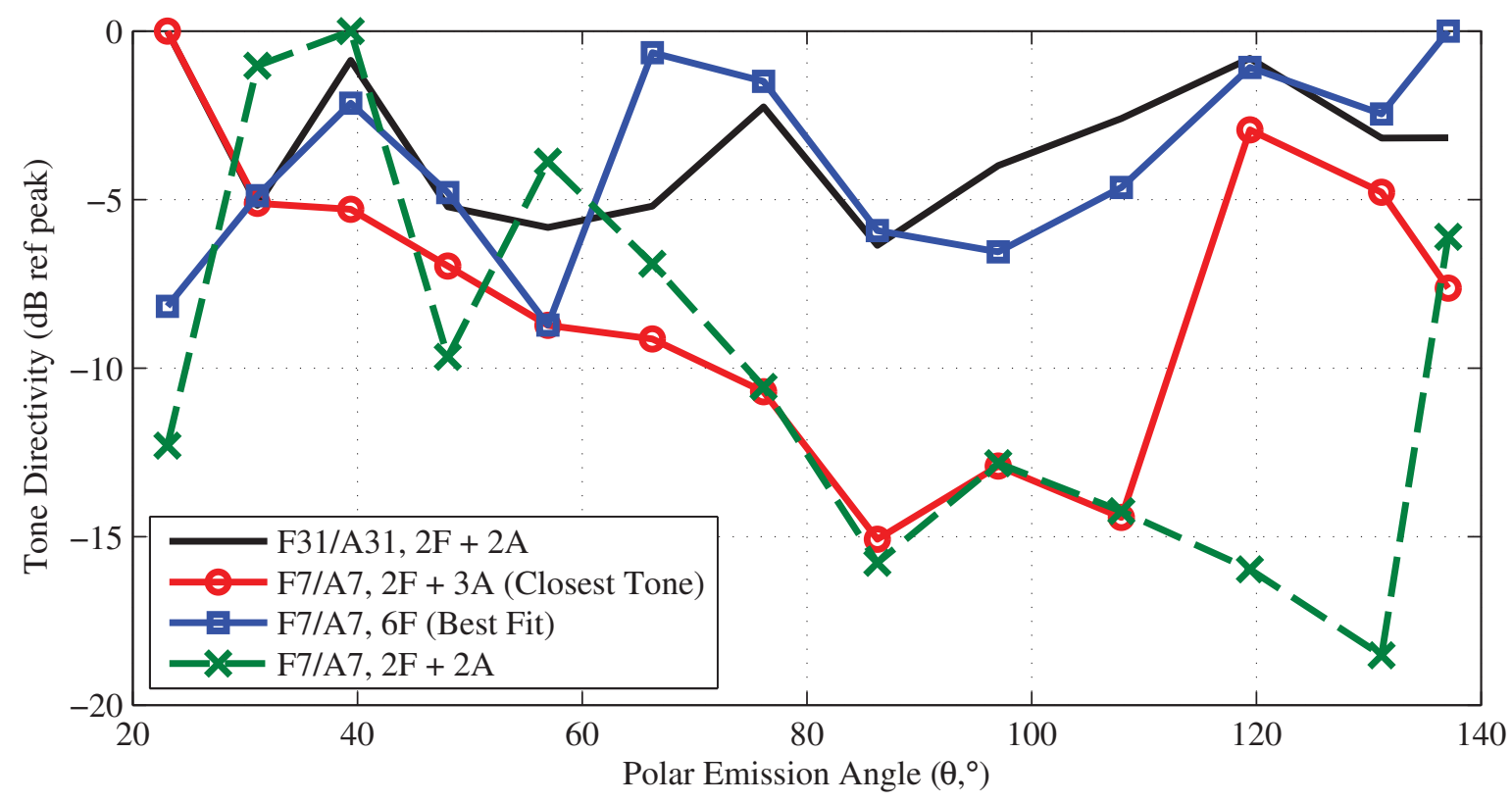

Figure 6. Directivity of F7/A7 tones within a one-third octave band centered on the F31/A31 2F+2A tone, for $\psi=0^{\circ}$.

\section{Direct Difference - Concept and Implementation}

The direct difference method assumes that, within a $1 / 3^{\text {rd }}$ octave band, the suppression map for the F7/A7 source is directly applicable to the equivalent $1 / 3^{\text {rd }}$ octave band of an arbitrary rotor. This method preserves the source energy within a given frequency band. The direct difference method proceeds through the boxed region of the flow chart in Fig. 3, using an isolated reference source (IRS) and a shielded reference source (SRS) from the LSAF PAA data set to construct a suppression map. This suppression map, in this case constructed on a $1 / 3^{\text {rd }}$ octave band basis, is then directly applied to a $1 / 3^{\text {rd }}$ octave band spectrum of the isolated source of interest (ISI), which is the alternative rotor noise source, to generate a direct difference estimate of the shielded source of interest (DDSI). The $1 / 3^{\text {rd }}$ octave band operations of the direct difference method are not included in the flow chart.

While this method preserves the source energy within a given frequency band, it does not directly account for differences in individual tone frequencies or directivities. As mentioned previously, a tone in one data set may map to a different family of tones in another data set when scaled to full-scale. Different families of tones may have dramatically different directivity patterns. ${ }^{16}$ As source directivity should play a major role in how an acoustic field scatters about a body for a given frequency, an additional method which utilizes the measured source directivity should be considered in the processing of this data.

\section{Tone Matching - Concept and Implementation}

The tone matching method is considered a higher-fidelity method than direct difference, and attempts to preserve source directivity with some trade-off in the accuracy of frequency content. Following the flow chart, the noise suppression is still calculated from the LSAF PAA database. However, individual tones and their directivity are identified in both the unshielded LSAF PAA data and the arbitrary, isolated source of interest. Within a selected frequency range of an ISI tone's center frequency, the F7/A7 tone with the directivity closest to the ISI's tone directivity is identified, and the suppression for this F7/A7 tone is applied to the ISI tone. In contrast to the direct difference method, the tone matching method attempts to capture the tone directivity specific to a given installed blade set. This is a similar concept, but different in execution compared to corresponding work by Guo et al. ${ }^{11}$

The need for a tone matching method is illustrated by Fig. 6. For this particular F31/A31 2F+2A tone, F7/A7 tones within a full-scale, one-third octave band centered on this 2F+2A F31/A31 tone are matched. A total of $7 \mathrm{~F} 7 / \mathrm{A} 7$ tones fall within the octave band, although only two are shown in Fig. 6, along with 
the F7/A7 2F+2A for reference. The F7/A7 2F+3A tone from the LSAF PAA data set is the closest tone to the F31/A31 data in terms of frequency. However, the F7/A7 2F+3A tone directivity does not show particularly strong agreement with the F31/A31 2F+2A tone directivity. The F7/A7 6F tone has the lowest mean-square directivity difference from the F31/A31 2F+2A tone. As a result, the tone matching method uses the F7/A7 6F tone shielding information and applies it to the F31/A31 2F+2A tone. Note that while the LSAF PAA data set includes information at multiple azimuth angles, the F31/A31 data set only has data available at a single value of $\psi$. Thus, this procedure is artificially limited here to only match directivity along a single line of constant $\psi$. As is shown later, azimuthal directivity contains critical information for suppression maps.

As with the direct difference method, three data sets are required: IRS, SRS, and ISI. For the companion system noise assessment, ${ }^{13}$ the two Reference Source inputs are taken from the LSAF PAA database, while the Source of Interest is taken from the F31/A31 database. However, this need not always be the case, particularly when performing a case study of tone matching. The processing methodology of Fig. 3 is given in detail.

1. Identify the tones in each data set

2. Correct the tones in the SRS data set for frequency shifts and haystacking, as discussed in the previous section.

3. The synthetic SRS is angle-by-angle, frequency-by-frequency, subtracted from the IRS to construct a suppression map with frequencies labeled as either tone-related or broadband.

4. $\psi=0^{\circ}$ tone directivities are extracted for both the IRS and the ISI. For each ISI tone, the IRS tone within $\pm 1 / 6^{\text {th }}$ of an octave of the ISI tone, with the lowest normalized mean-square error from the ISI tone, is associated with the ISI tone. This mean-square error is calculated using a normalized directivity, where the peak in $\mathrm{dB}$ is subtracted from the polar arc SPL. If the lowest error is still large, greater than $100 \%$ normalized mean-square error, the search range is expanded to \pm half of an octave.

5. This tone association is used in conjunction with the shielding table to individually shield each tone in the ISI data set, and then shield the remaining broadband data. Broadband shielding is determined by constructing curve-fits to the non-tonal frequency bins in the spectra.

6. This tone-matched estimate of the shielded source of interest (TMSI) is now available as an input to a system noise assessment routine, or optionally for comparison with a known solution, the true Shielded Source of Interest (SSI), if available.

In principle, tone matching is expected to provide a better estimate of shielding than direct difference. The tone matching technique uses additional physical information (source directivity) in computing shielding, as compared to a direct difference octave-band mapping method. However, significant differences in rotor designs or experimental conditions may have a strong effect on the process. A simple case study may illuminate the behavior of the tone matching method, as well as the direct difference method, in the context of a system noise assessment.

\section{Case Study}

Within the LSAF PAA database, a wide variety of rotor and shielding configurations were measured. While the LSAF experiment was not designed with these techniques in mind, it is sufficiently comprehensive that a search of the test matrix yields several situations where a reference rotor was operated in both isolated and shielded (IRS and SRS) configurations. The reference rotor (source) was then altered and again operated in both isolated and shielded configurations. Using these two different sources in both isolated and shielded configurations allows evaluation of the shielding calculation from both the DDSI and the TMSI.

From the database, two combinations of sources and shielding are selected for evaluation. These are summarized in Table 1. The first combination, labeled Case 1, maintains the spectral content of the data between the reference and interest configurations by holding the forward and aft rotor rotation rates (shaft speeds) constant. However, the directivity of the sources varies. The F7/A7 model was installed in a pusher configuration for the LSAF experiments, so the installation pylon wake was ingested by the rotors. ${ }^{10}$ In 
Table 1. LSAF PAA configurations for case study shielding calculations.

\begin{tabular}{|c|c||c|c|c|}
\hline & & $\begin{array}{c}\text { Engine Position } \\
\text { Upstream from TE } \\
(x / D)\end{array}$ & $\begin{array}{c}\text { FWD/AFT } \\
\text { Shaft Speed } \\
(\mathrm{RPM})\end{array}$ & $\begin{array}{c}\text { Included } \\
\text { Effects }\end{array}$ \\
\hline \hline Case 1 & IRS & N/A & $12600 / 14000$ & N/A \\
Constant spectral content & SRS & 1.0 & $12600 / 14000$ & N/A \\
Varied directivity & ISI & N/A & $12600 / 14000$ & Pylon Blowing \\
& SSI & 1.0 & $12600 / 14000$ & Pylon Blowing \\
\hline Case 2 & IRS & N/A & $12600 / 14000$ & N/A \\
Varied spectral content & SRS & 1.0 & $12600 / 14000$ & N/A \\
Similar directivity & ISI & N/A & $14400 / 16000$ & N/A \\
& SSI & 1.0 & $14400 / 16000$ & N/A \\
\hline
\end{tabular}

some configurations, pressurized air was used to fill the pylon wake and have more uniform flow entering the rotor. This pylon blowing alters the noise levels and directivity of the open rotor source. ${ }^{13}$

The second combination, labeled Case 2, alters the spectral content of the data by changing the rotor shaft speeds. This may have some effect on the shielding directivity, as for a given tone the wavelength-tobody size ratio changes, causing scattering characteristics to be different. This is considered a severe test case, in that it may push all matchable tones out of acceptable frequency bounds.

For both cases, the facility Mach number is held constant at 0.24 and the rotor and shielding model angles of attack are both $0^{\circ}$. The airframe planform is the simplest configuration available, with no deflected surfaces, no vertical tails, and no acoustic liners. As given in the table, the shielding is computed for a rotor location of one rotor diameter upstream of the airframe trailing edge. As the physical rotor hardware does not change, in both cases this corresponds to the same physical location of the rotor as well.

\section{Case Evaluation}

The one available data set, SSI, and the two applied suppression techniques, TMSI and DDSI, are flown along a straight, level flight path in the ANOPP2 package, simulating free-flying shielded rotor sources with no additional aeroacoustic effects. The flight path is similar to that used in recent auralization studies. ${ }^{17}$ The EPNL values at a single flyover $\left(\psi=0^{\circ}\right)$ observer location are computed and the difference is shown in Table 2 for both cases. As shown, both of the methods have similar differences for a given case when compared to the EPNL computed using the SSI data set. Tone matching shows slightly higher levels than direct difference, but both show similar changes. Both are very close to the experiment solution on the system level, where a configuration change may alter an assessment output by several EPNL $\mathrm{dB}$. The details of the differences are assessed in the following sections.

\section{Case 1}

To evaluate the overall difference between the data sets, the EPNL calculation must be decomposed. EPNL is computed by integrating the tone-corrected perceived noise level (PNLT). The PNLT (without ground effects) for the observer in Case 1 is shown in Fig. 7, for all three input data sets. Here, all three data sets show similar trend and shape. The difference between the results is most pronounced between polar angles of $50^{\circ}$ and $120^{\circ}$. In particular, tone matching is slightly higher in the $50^{\circ}$ to $80^{\circ}$ arc. The maximum difference within this region occurs at $73^{\circ}$.

Table 2. $\triangle \mathrm{EPNLdB}$ calculations for test case data.

\begin{tabular}{|c||c|c|}
\hline Case & TMSI - SSI & DDSI - SSI \\
\hline \hline 1 & 0.61 & 0.26 \\
\hline 2 & 2.38 & 2.10 \\
\hline
\end{tabular}




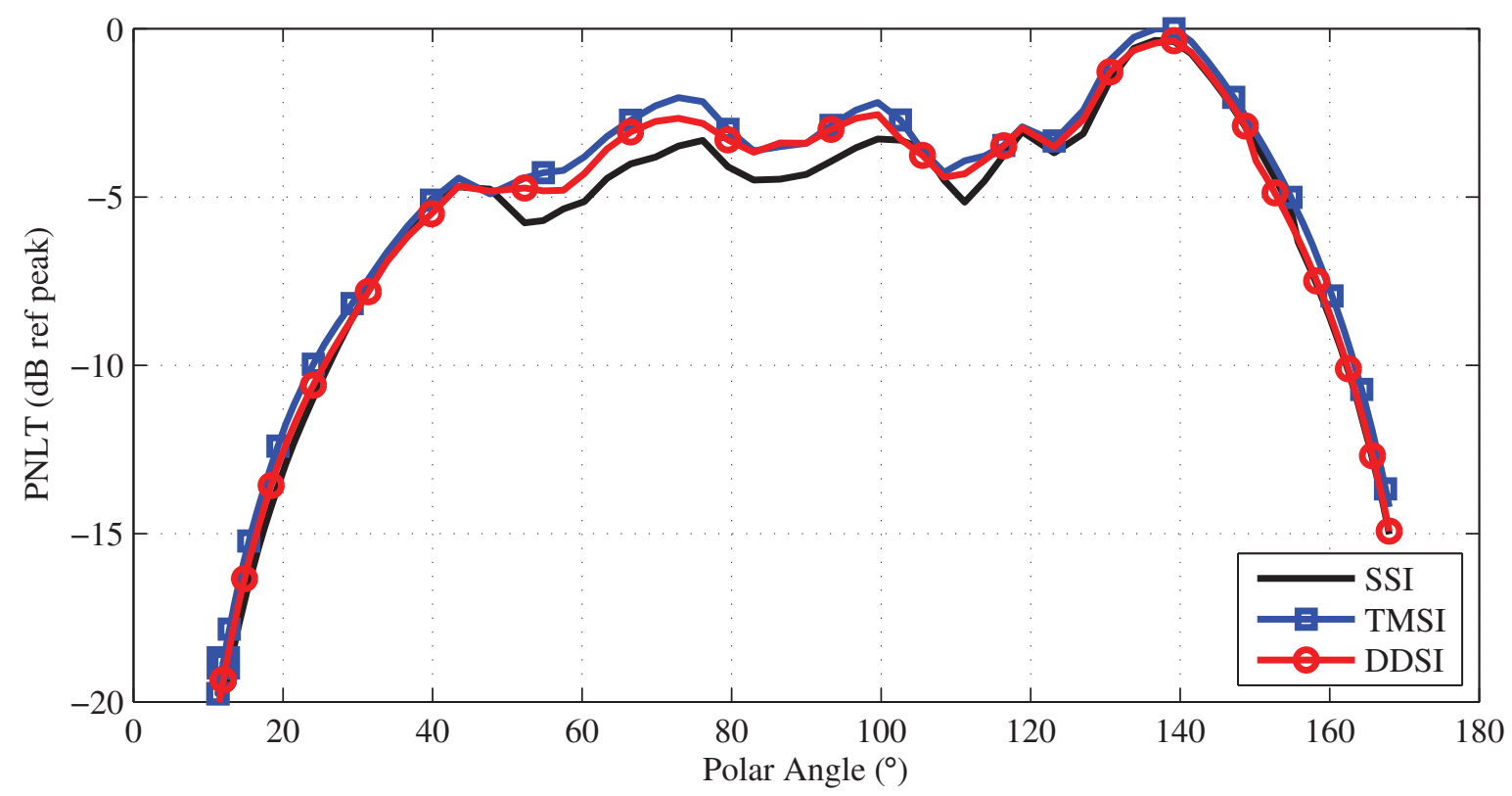

Figure 7. Case 1 PNLT values as a function of emission angle for a flyover observer $\left(0^{\circ}\right.$ azimuth $)$.

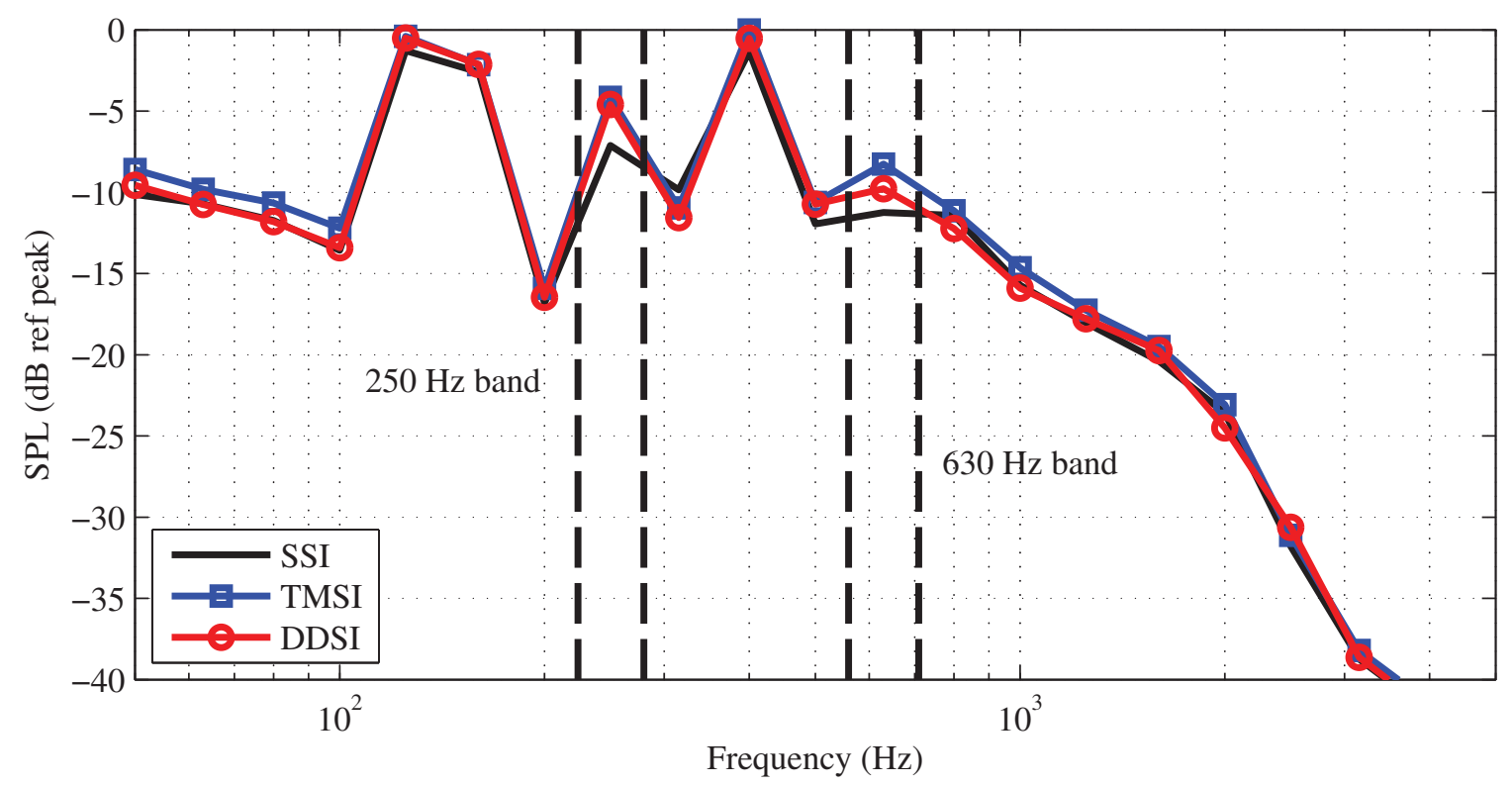

Figure 8 . Case $11 / 3^{\text {rd }}$ octave band spectrum at a $73^{\circ}$ emission angle. 
The $1 / 3^{\text {rd }}$ octave band spectrum at $73^{\circ}$ is shown in Fig. 8 . The full spectrum extends from $50 \mathrm{~Hz}$ to $10 \mathrm{kHz}$, but it is truncated to $5 \mathrm{kHz}$ here to highlight data of interest. Differences between the SSI, TMSI, and DDSI predictions are evident within several frequency ranges of the spectrum. While there are many frequency bands which may be examined in more detail, two $1 / 3^{\text {rd }}$ octave bands are isolated for further investigation: (1) the $250 \mathrm{~Hz}$ band, where tone matching and direct difference agree with each other but disagree with the experimental data by approximately $2.5 \mathrm{~dB}$, and (2) the $630 \mathrm{~Hz}$ band, where tone matching and direct difference show significant difference between both each other and the experimental data. Note that the tone matching process can be evaluated on a narrowband basis, tone-by-tone, where individual tone suppression maps and directivities can be compared. Because direct difference data do not exist on a narrowband, tone-by-tone level, the direct difference method cannot be evaluated in this way.

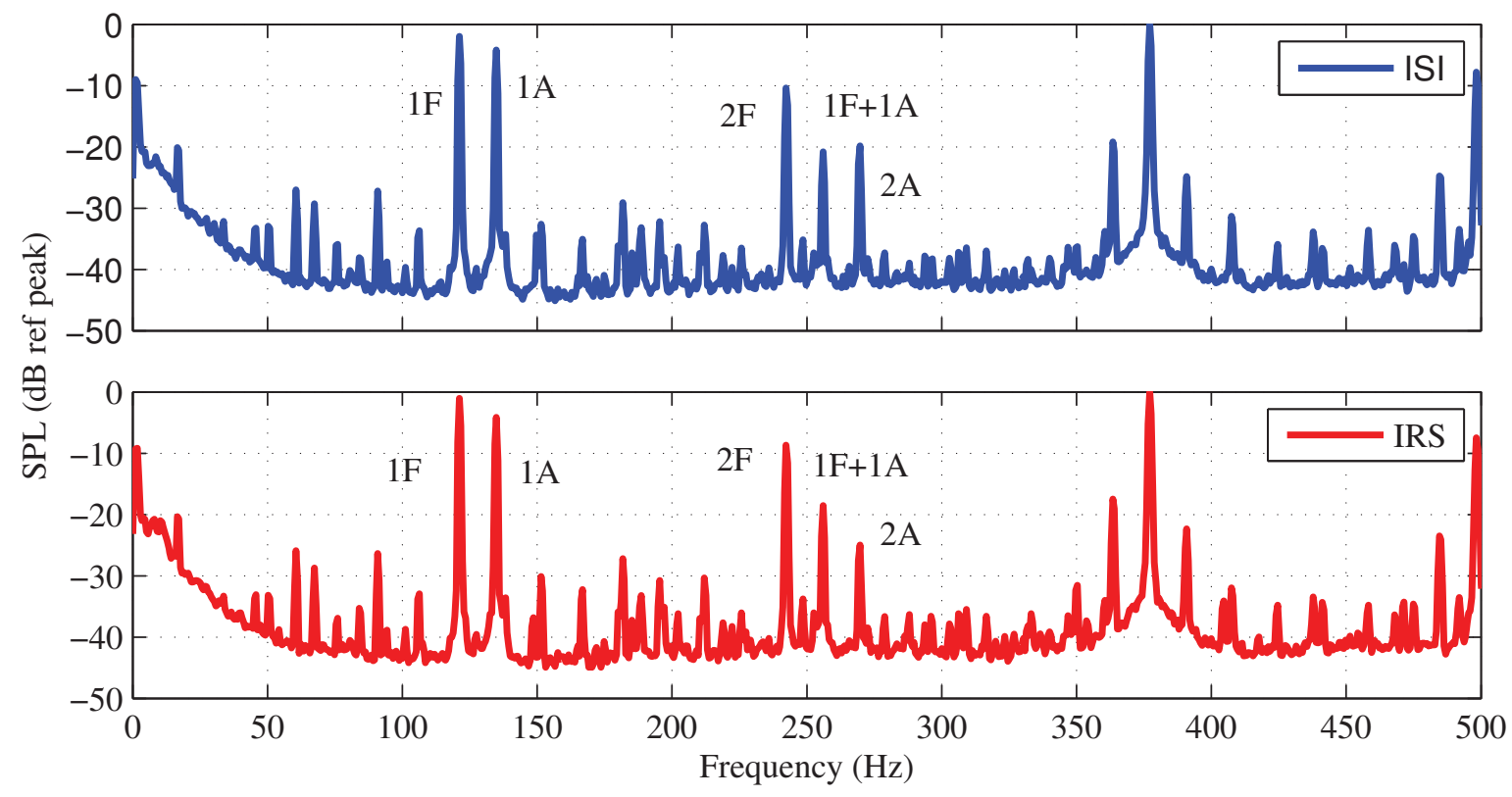

Figure 9. Case 1 ISI and IRS normalized spectra at $(\theta, \psi)=\left(86^{\circ}, 0^{\circ}\right)$, full-scale frequency.

The plots in Fig. 9 show that the $250 \mathrm{~Hz} 1 / 3^{\text {rd }}$ octave band contains three tones in the ISI dataset: the $2 \mathrm{~F}$, the $1 \mathrm{~F}+1 \mathrm{~A}$, and the $2 \mathrm{~A}$. These are associated, respectively, with the $2 \mathrm{~F}, 1 \mathrm{~F}+1 \mathrm{~A}$, and $2 \mathrm{~A}$ tones of the IRS data set, as may be expected for a moderate directivity change which maintains source spectral content. Inspection of these tone matches shows that they are reasonably matched. The difference between suppression maps, $\Delta d B_{\text {diff }}$, for the matches are shown in Fig. 10. Fig. 10a shows the difference in the $2 \mathrm{~F}$ tone match. The largest magnitude differences manifest at peaks and troughs in the flyover arc $\left(\psi=0^{\circ}\right)$. These are at polar angles of $\theta \leq 40^{\circ}$, which are not particularly suspicious in the PNLT plot of Fig. 7, meaning they are not likely dominant sources of differences in the EPNL levels. Similarly, the $1 \mathrm{~F}+1 \mathrm{~A}$ tone match difference in Fig. 10b has peaks at polar angles less than $\theta=60^{\circ}$. This, too, is not considered further here.

The 2A tone match difference in Fig. 10c, however, shows a strong difference along the $\psi=0^{\circ}$ polar arc at the angles of interest between $\theta=50^{\circ}$ and $\theta=80^{\circ}$. The individual tone directivities are shown in Fig. 11a and Fig. 11b. Here, while major features appear to remain the same between the ISI and IRS data sets, the directivity pattern shifts slightly in the positive $\psi$ direction. This shift leads to a steep gradient in the difference between the two data sets. The difference is shown in Fig. 11c, and occurs along the same directivity region as the suppression map difference. This suggests that, as might be expected, strong differences between the ISI and IRS datasets will lead to local differences in the tone matching calculation. From the $1 / 3^{\text {rd }}$ octave band spectrum, this appears to be a common effect in both the direct difference and tone matching methods.

The ISI data have six blade harmonic tones within the $630 \mathrm{~Hz} 1 / 3^{\text {rd }}$ octave band (not shown). Listed in ascending frequency order, these are $5 \mathrm{~F}, 4 \mathrm{~F}+1 \mathrm{~A}, 3 \mathrm{~F}+2 \mathrm{~A}, 2 \mathrm{~F}+3 \mathrm{~A}, 1 \mathrm{~F}+4 \mathrm{~A}$, and $5 \mathrm{~A}$. The first five of these tones are matched to their corresponding tones in the IRS data. However, the 5A tone of the ISI data gets 


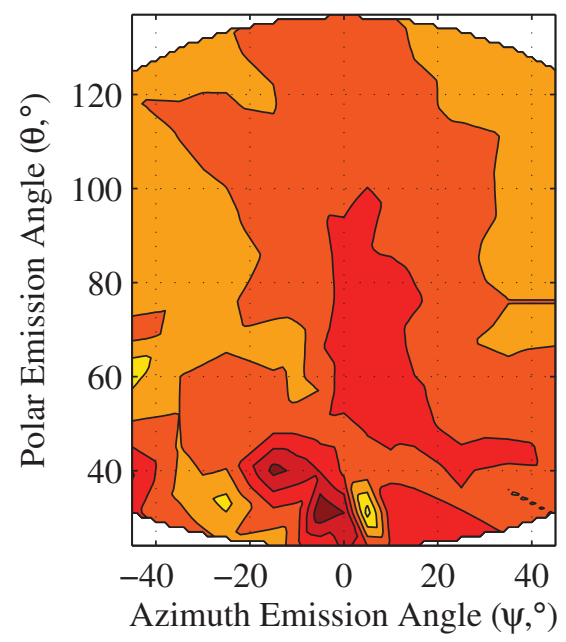

(a) $\Delta d B_{\text {diff }}$ for the $2 \mathrm{~F}$ tone.
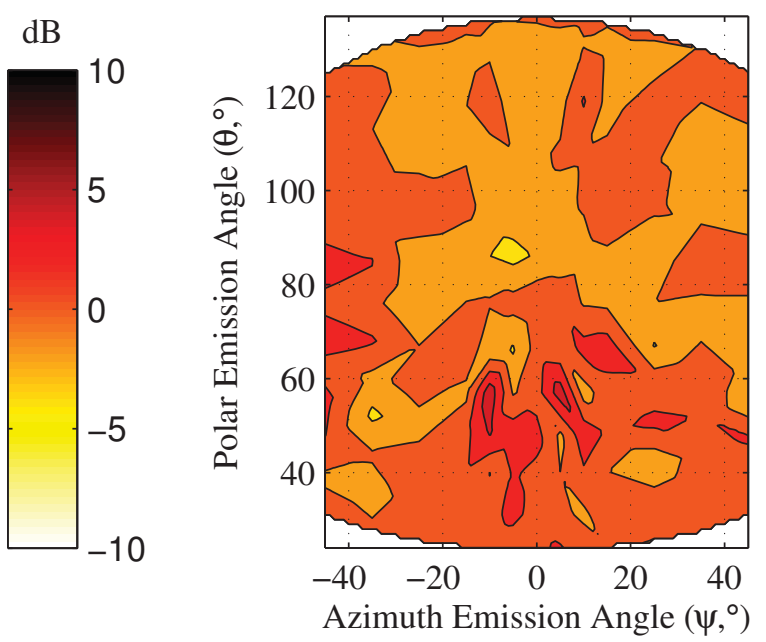

(b) $\Delta d B_{\text {diff }}$ for the $1 \mathrm{~F}+1 \mathrm{~A}$ tone.
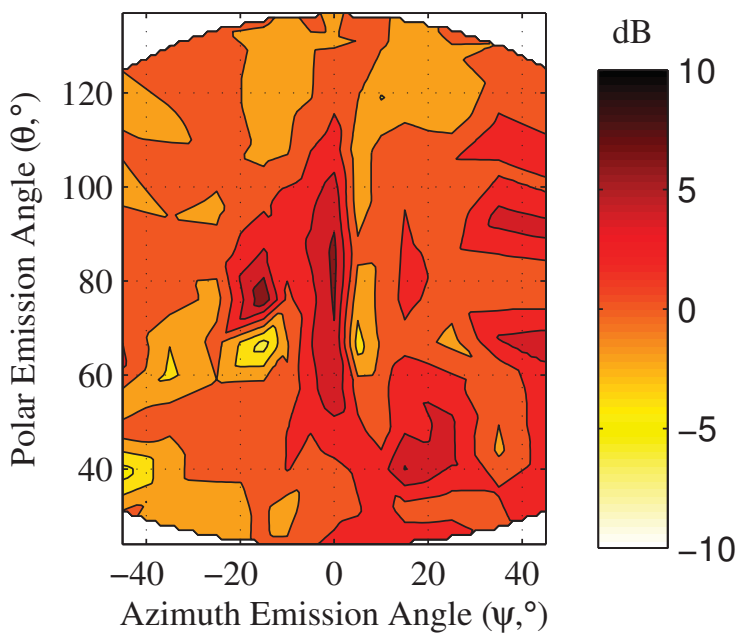

(c) $\Delta d B_{\text {diff }}$ for the $2 \mathrm{~A}$ tone.

Figure 10. Case 1 suppression map differences for the tones in the $250 \mathrm{~Hz} 1 / 3^{\text {rd }}$ octave band. Plots have contour spacing of $2 \mathrm{~dB}$. 


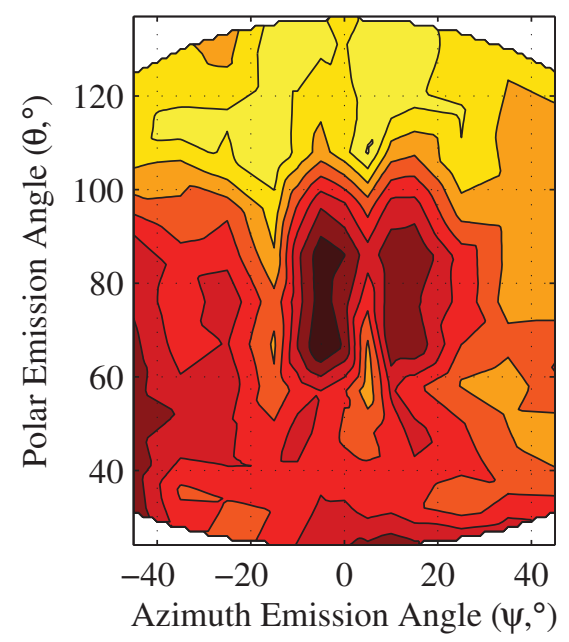

(a) ISI $2 \mathrm{~A}$ tone (dB ref peak).

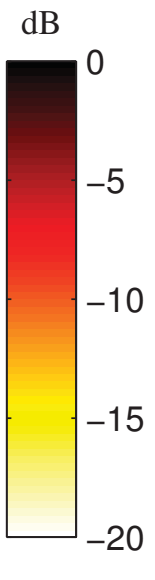

20

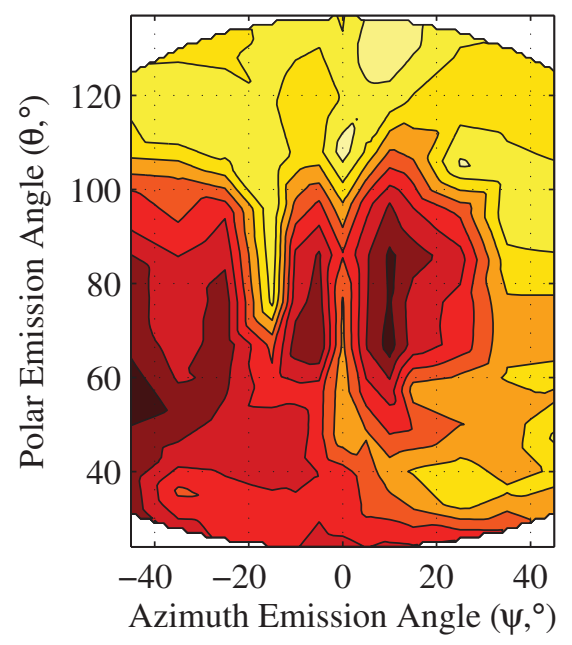

(b) IRS $2 \mathrm{~A}$ tone (dB ref peak).
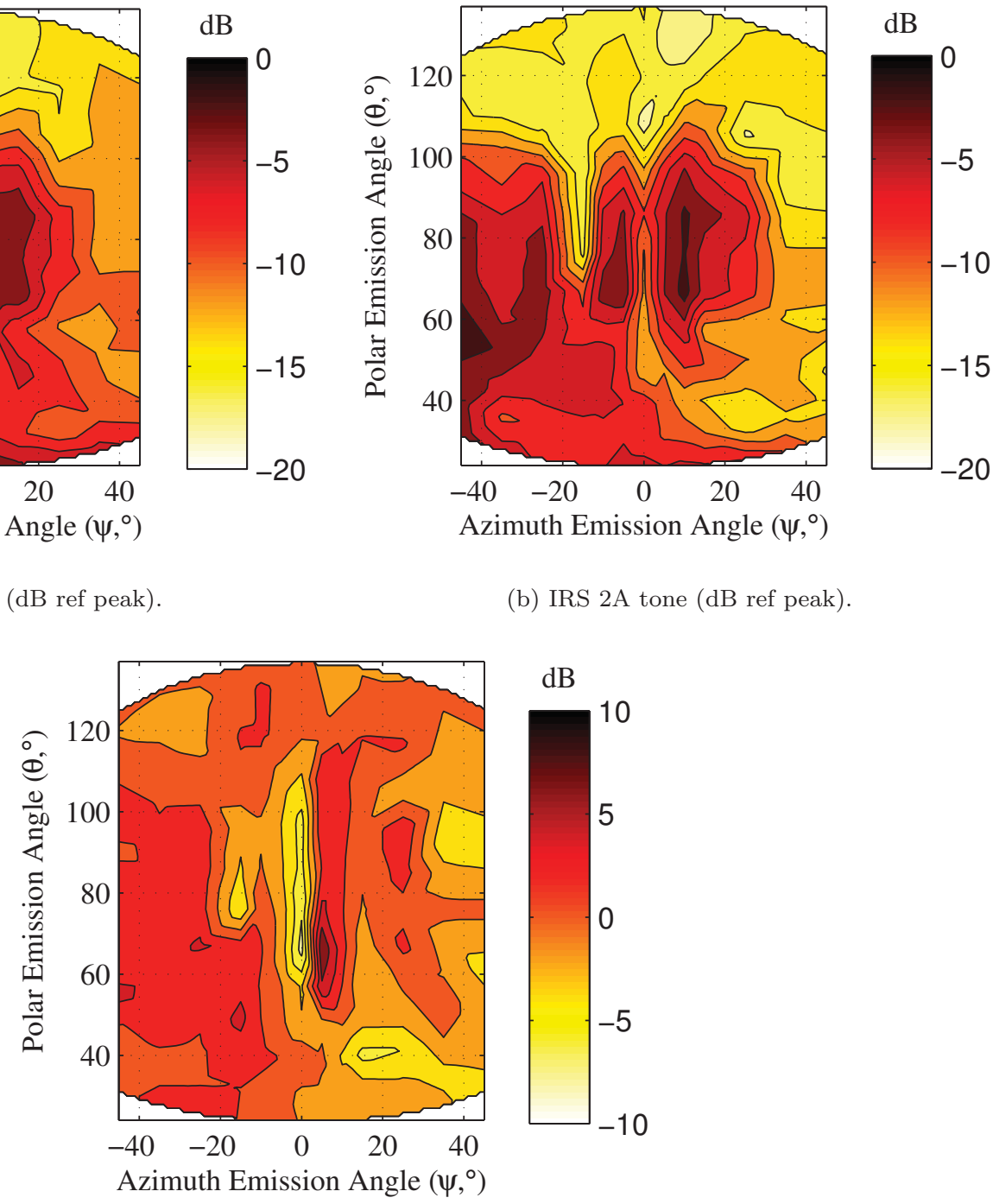

(c) IRS 2A directivity - ISI 2A directivity.

Figure 11. Case $12 \mathrm{~A}$ tone isolated behavior change from ISI to IRS. Plots have contour spacing of $2 \mathrm{~dB}$. 
matched to the $6 \mathrm{~A}$ tone of the IRS data. This match occurs outside of the $\pm 1 / 6^{\text {th }}$ octave standard search range, as all of the tones within the initial search range had high normalized rms errors, discussed previously.

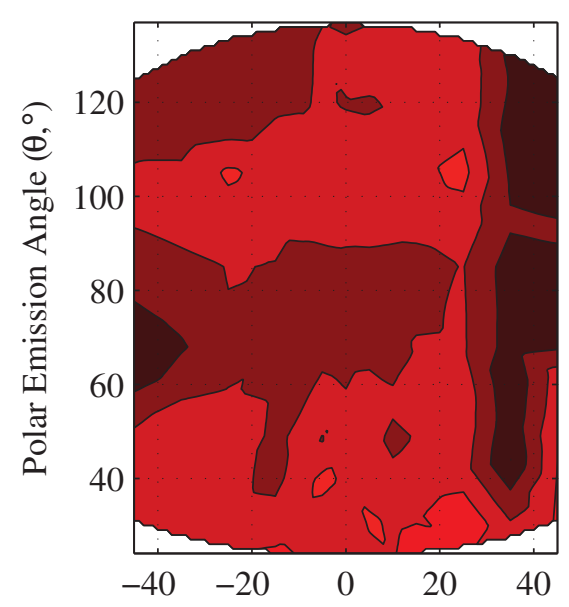

Azimuth Emission Angle $\left(\psi,{ }^{\circ}\right)$

(a) ISI 5A tone (dB ref peak).

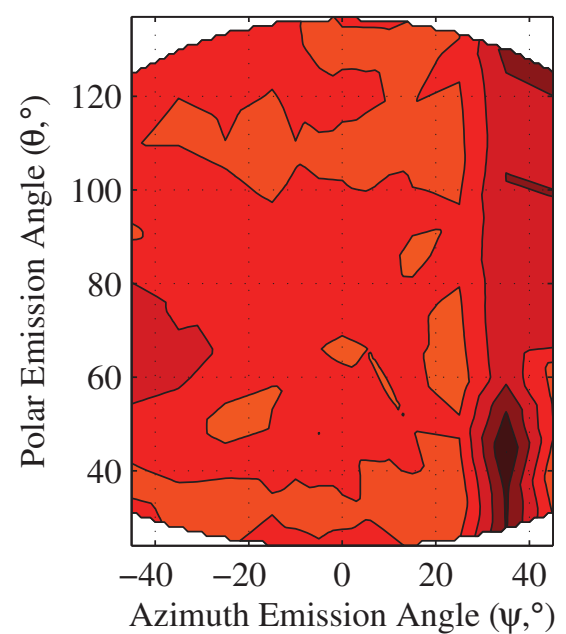

(c) IRS 6A tone (dB ref peak).
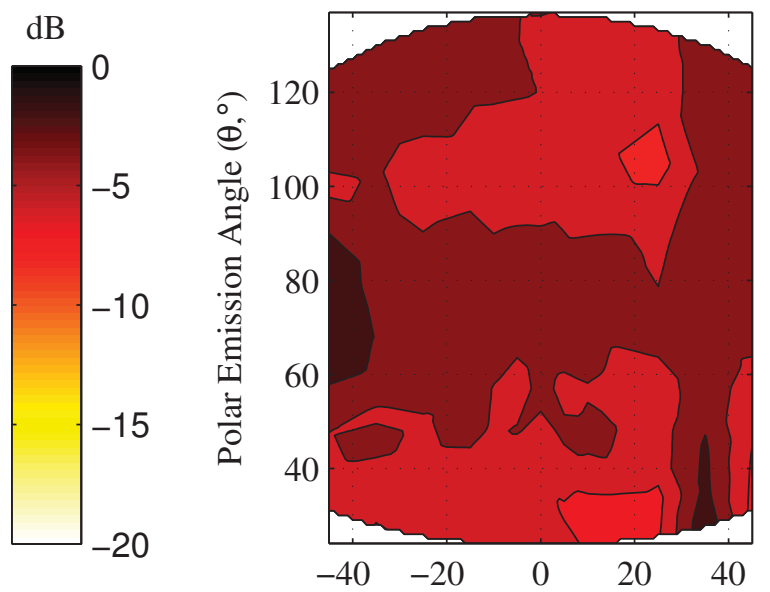

$\mathrm{dB}$

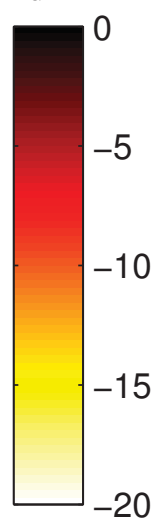

Azimuth Emission Angle $\left(\psi,{ }^{\circ}\right)$

(b) IRS 5A tone (dB ref peak).

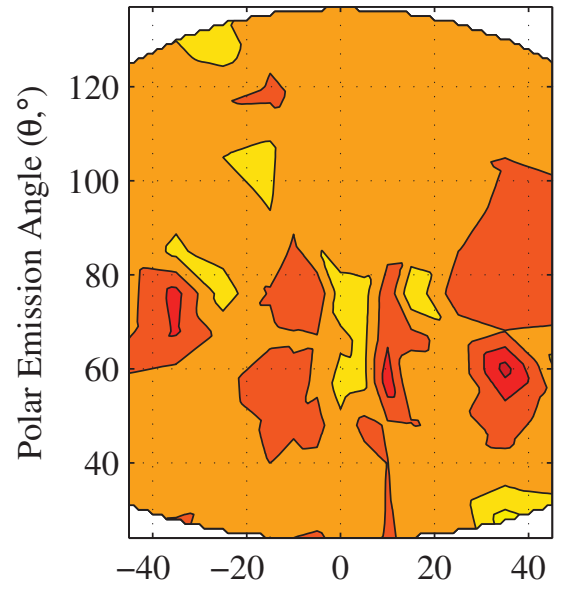

$\mathrm{dB}$

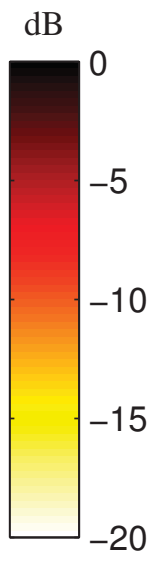

Azimuth Emission Angle $\left(\psi,{ }^{\circ}\right)$

(d) $\Delta d B_{\text {diff }}$ for the $5 \mathrm{~A}$ tone.

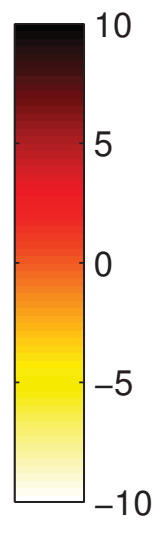

Figure 12. Case 1 directivity plots for the tone matching of ISI 5A, along with the associated suppression map difference. Plots have contour spacing of $2 \mathrm{~dB}$.

All of these tone matches may play a role in the difference between the methods and the experimental result. However, for the purposes of method discussion, only the $5 \mathrm{~A}$ fit is addressed here to show how the methods are applied to mis-matched data. The ISI 5F tone directivity is plotted in Fig. 12a along with the IRS 5A tone directivity in Fig. 12b and the IRS 6A tone directivity in Fig. 12c. Upon visual inspection, it might appear that the normalized directivity of the IRS 5A tone would show a better match to the ISI $5 \mathrm{~A}$ tone than the IRS 6A tone. However, it should be recalled that only the $\psi=0^{\circ}$ polar arc is used in the actual algorithm normalization and directivity fitting. These directivity arcs are shown in Fig. 13. From this perspective, it is evident that using a limited cut along $\psi=0^{\circ}$ of the data can lead to poor fits when total tone directivity is considered. For a portion of the directivity curve the IRS $5 \mathrm{~A}$ tone is a much better fit than the IRS $6 \mathrm{~A}$ tone, but from a mean-square error calculation, the IRS $6 \mathrm{~A}$ tone is matched. For reference, the suppression map difference is shown in Fig. 12d. While none of the difference regions have extreme values, overall the data are negative along the $\psi=0^{\circ}$ polar arc, with a noticeably lower level in the flyover region where $60^{\circ}<\theta<80^{\circ}$. However, this behavior does not account for the octave band being higher for TMSI 


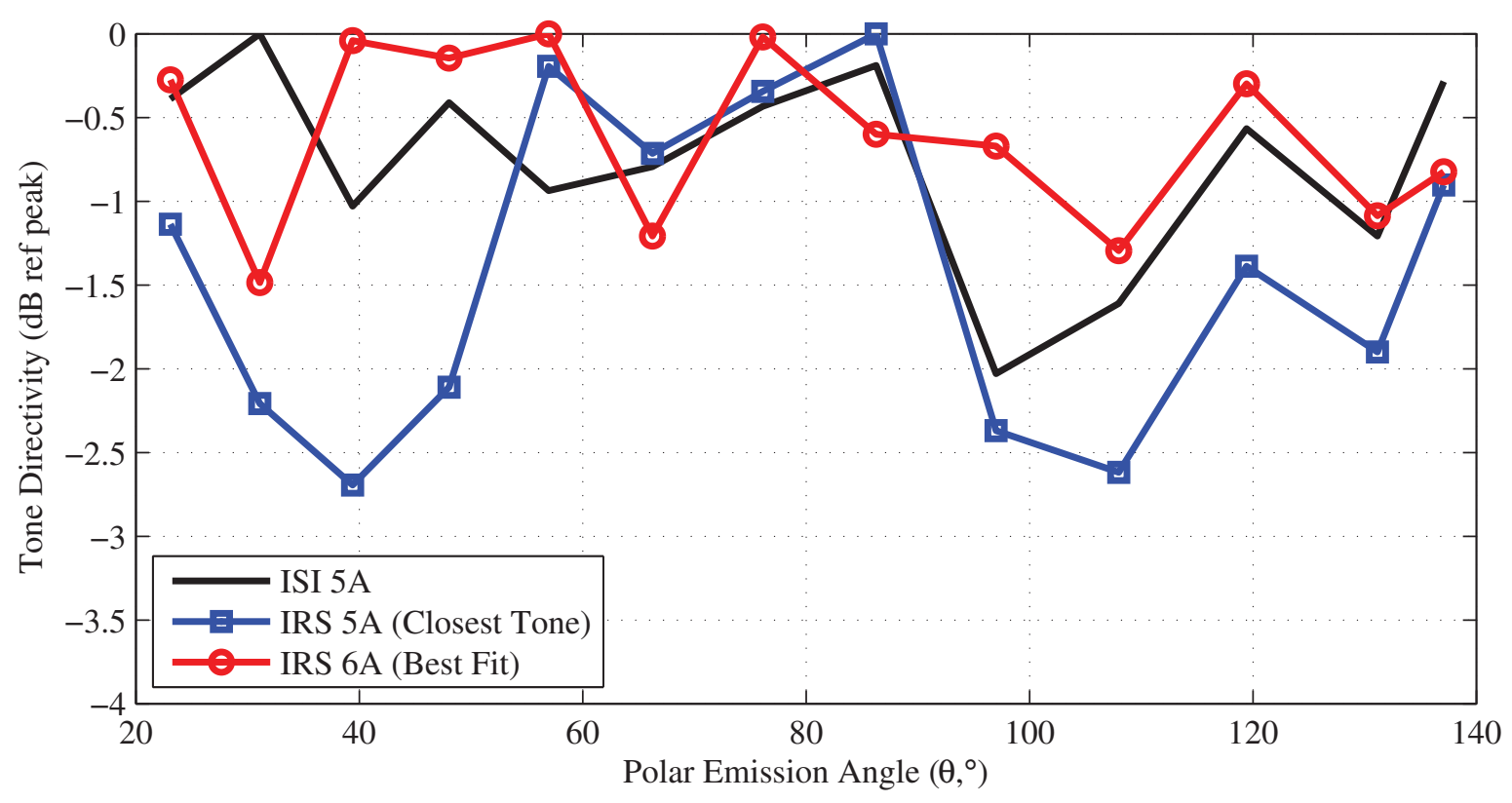

Figure 13. Case $1 \psi=0^{\circ}$ directivity plots for the tone matching of ISI 5A.

than SSI, but evaluation of the data shows that the $6 \mathrm{~A}$ tone is between 10 and $20 \mathrm{~dB}$ below the other tones within this octave band for ISI, and nearly $5 \mathrm{~dB}$ below the other tones in SSI. It is not the major contributor in this octave band, but is an interesting tone for evaluation and discussion.

\section{Case 2}

Case 2, where the rotor RPM (and thus frequency content) is shifted, as shown in Fig. 14, is now considered. The PNLT for the observer in Case 2 is shown in Fig. 15, for all three input data sets. Unlike with Case 1, here both the TMSI and DDSI data sets show significant shape difference from the SSI data for the entire range of the data. At $\theta=111^{\circ}$, all three data sets are different in both level and shape, so this polar angle is selected for further investigation.

As expected, the octave band spectra of the predictions at this directivity, seen in Fig. 16, shows significant differences between data sets. While the differences span most of the acoustic spectrum, two $1 / 3^{\text {rd }}$ octave bands in particular, $250 \mathrm{~Hz}$ and $500 \mathrm{~Hz}$, stand out. At $250 \mathrm{~Hz}$ there is a large difference between both methods and the experimental data, with the tone matching method having the largest peak value. At 500 $\mathrm{Hz}$ the direct difference and tone matching methods agree, but show a large increase over the SSI data. Because the $250 \mathrm{~Hz}$ band captures both the peak of the tone matching prediction and shows the most difference between methods, it is considered further.

Within the $250 \mathrm{~Hz} 1 / 3^{\text {rd }}$ octave band, once Doppler effects at $\theta=111^{\circ}$ are considered, the rotor tones present in the ISI data set are the $2 \mathrm{~F}$ and the $1 \mathrm{~F}+1 \mathrm{~A}$ tones. Of these, the $1 \mathrm{~F}+1 \mathrm{~A}$ is selected for further evaluation. This tone can only be matched with the IRS $2 \mathrm{~A}$ within $\pm 1 / 6^{\text {th }}$ of an octave of the $1 \mathrm{~F}+1 \mathrm{~A}$ frequency, and has sufficiently low error that it is not necessary to examine outside of the $\pm 1 / 6^{\text {th }}$ search area. The directivity of the ISI $1 \mathrm{~F}+1 \mathrm{~A}$ tone is shown in Fig. 17a, while the directivity of the IRS $2 \mathrm{~A}$ tone is shown in Fig. 17b. These tones have dissimilar directivity patterns. Their directivity along the $\psi=0^{\circ}$ polar arc is shown in Fig. 18. From this plot, it is evident that while the match may satisfy a minimum mean-square error criterion, it does not preserve the shape of the polar directivity of the tone. The suppression map difference is shown in Fig. 17c. As expected, a large peak in the difference is present in the vicinity of the $(\theta, \psi)=\left(111^{\circ}, 0^{\circ}\right)$ observer angle. This result suggests there is room for improvement to the tone matching algorithm by incorporating a more robust matching technique. It also suggests the potential for high error at a spectral level when no good match exists, but this limitation is shared by the direct difference method.

To summarize these results, the test cases show that the tone matching and direct difference methods have similar behavior when examining EPNL values, although the direct difference method shows slightly 


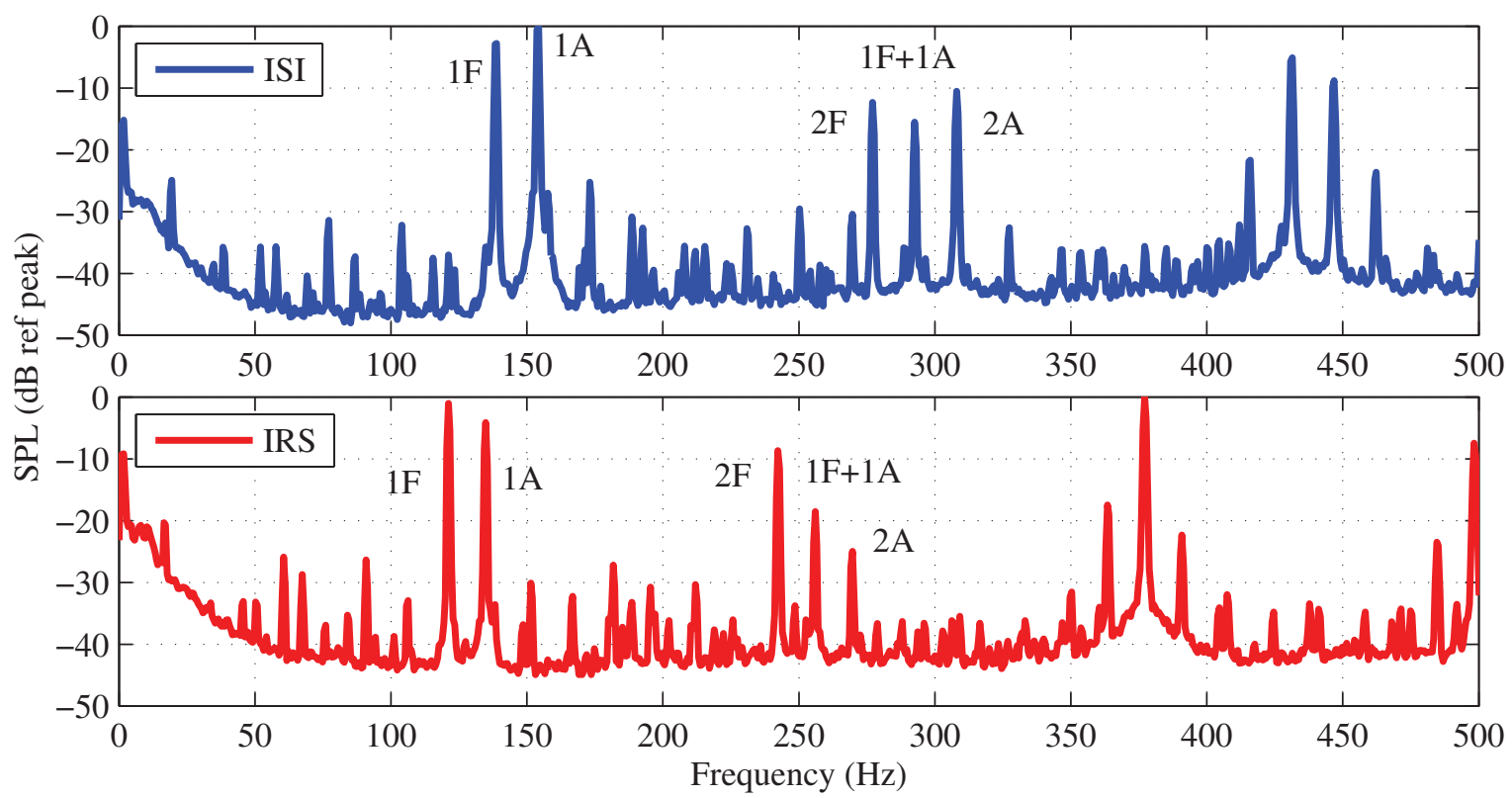

Figure 14. Case 2 ISI and IRS normalized spectra at $(\theta, \psi)=\left(86^{\circ}, 0^{\circ}\right)$, full-scale frequency.

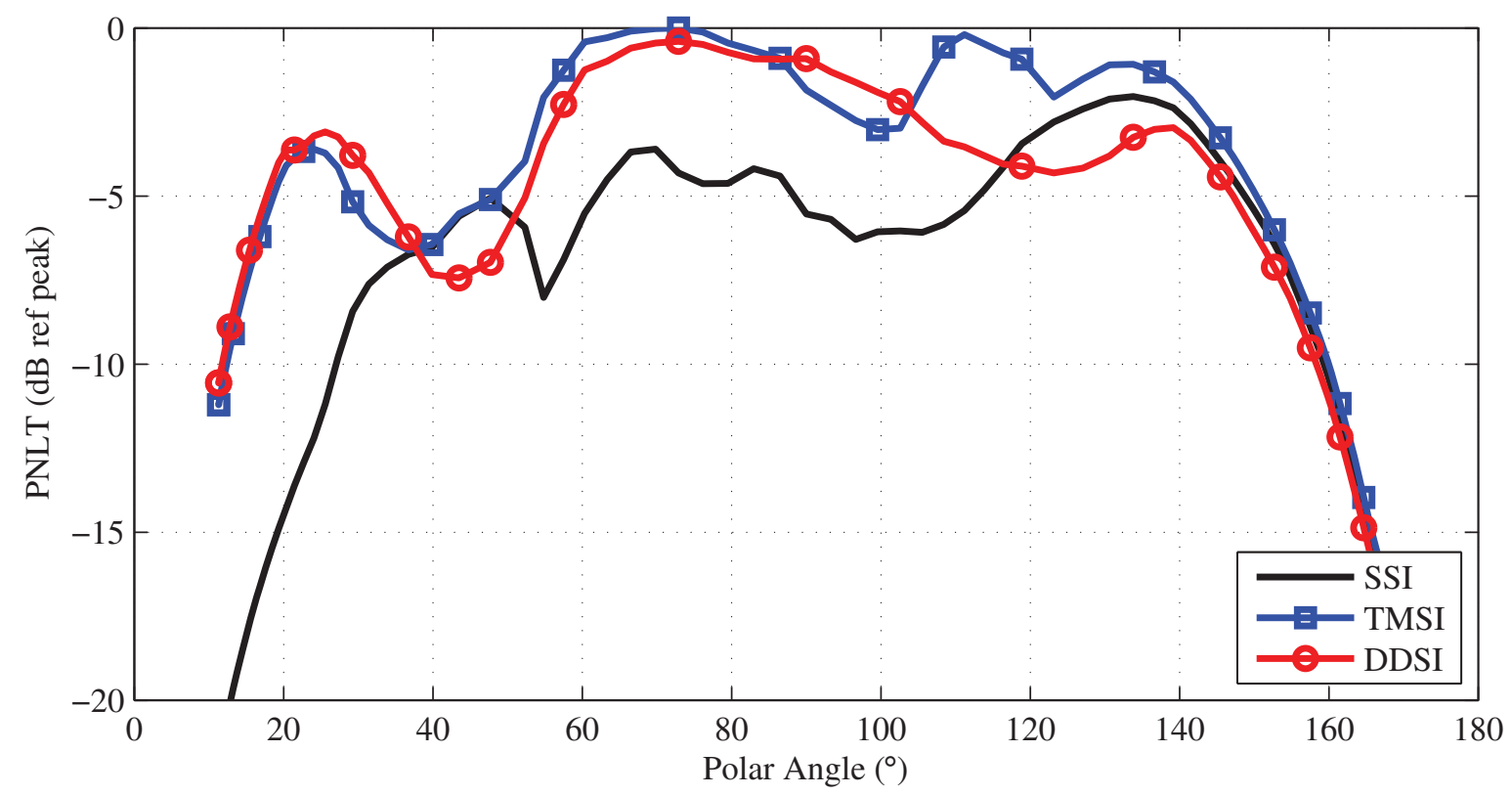

Figure 15. Case 2 PNLT values as a function of emission angle for a flyover observer ( $0^{\circ}$ azimuth). 


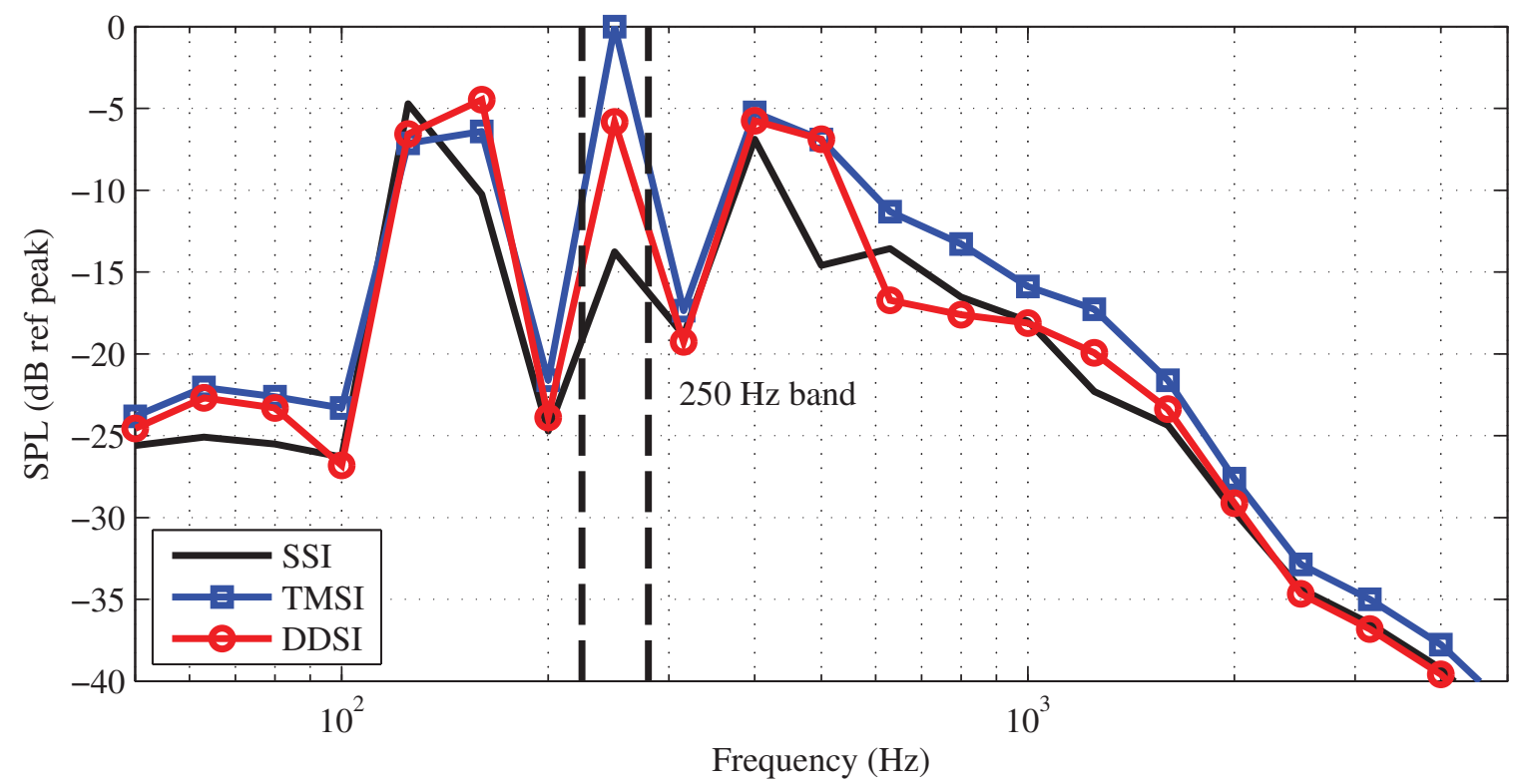

Figure 16. Case $21 / 3^{\text {rd }}$ octave band spectrum at a $111^{\circ}$ emission angle.

better agreement with a known answer when the same blade geometry (here the F7/A7) is used. Analysis of the tone matching method shows that, in Case 1, directivity changes of the source can lead to differences in octave band levels. However, these differences are similar in scale to differences seen in the direct difference method. A tone mismatch, as occurs in the Case $1630 \mathrm{~Hz}$ octave band, shows that limiting tone matching to a single directivity arc of the total map can lead to significant errors. Two important points are made from the Case 2 data. First, if no good tone fit exists within an acceptable frequency search range, tone matching results will suffer and likely stray from the desired suppression. Second, a more advanced, directivity shape preserving technique is needed which will allow better matching over a simple mean-square error method.

\section{Summary \& Future Work}

The evaluation of advanced open rotor aircraft concepts through system noise assessments currently requires data processing methods which use shielding suppression maps obtained experimentally with a legacy rotor design in combination with a future open rotor design. The methods addressed in this study are an initial attempt at such a process, and enable the application of measured installation effects to the projected isolated source noise of a future design. This process is valuable for the study of advanced concepts where open rotor engines are installed above an aircraft shielding structure to reduce community noise.

Two methods have been considered. One, direct difference, is an octave-band level correction, while the other, tone matching, addresses individual tones and matches them to similar tones based on the key parameters of directivity and frequency. The tone matching method is more complex and intensive to implement but is considered the higher fidelity method since it incorporates more source physics. Both methods are analyzed to provide guidance towards future refinement of the shielding application procedure.

The extensive PAA open rotor experimental database with the legacy rotor provides specific test cases with which to compare the performance of the direct difference and tone matching methods against a known solution from another experimental run. This is done through a simplified system noise assessment of an isolated blade set, shielded by a body, and flying on a simple flight path. Investigation of individual directivity angles and octave bands allows for more detailed evaluation of method behaviors.

For a test case where the directivity of the source is changed but the tones remain at the same frequency, both methods generate EPNL values close to the known values. When frequencies are shifted within the test case, direct difference results stray further from the known solution, although remain slightly closer than tone matching. Even though the direct difference method performed better than the tone matching 

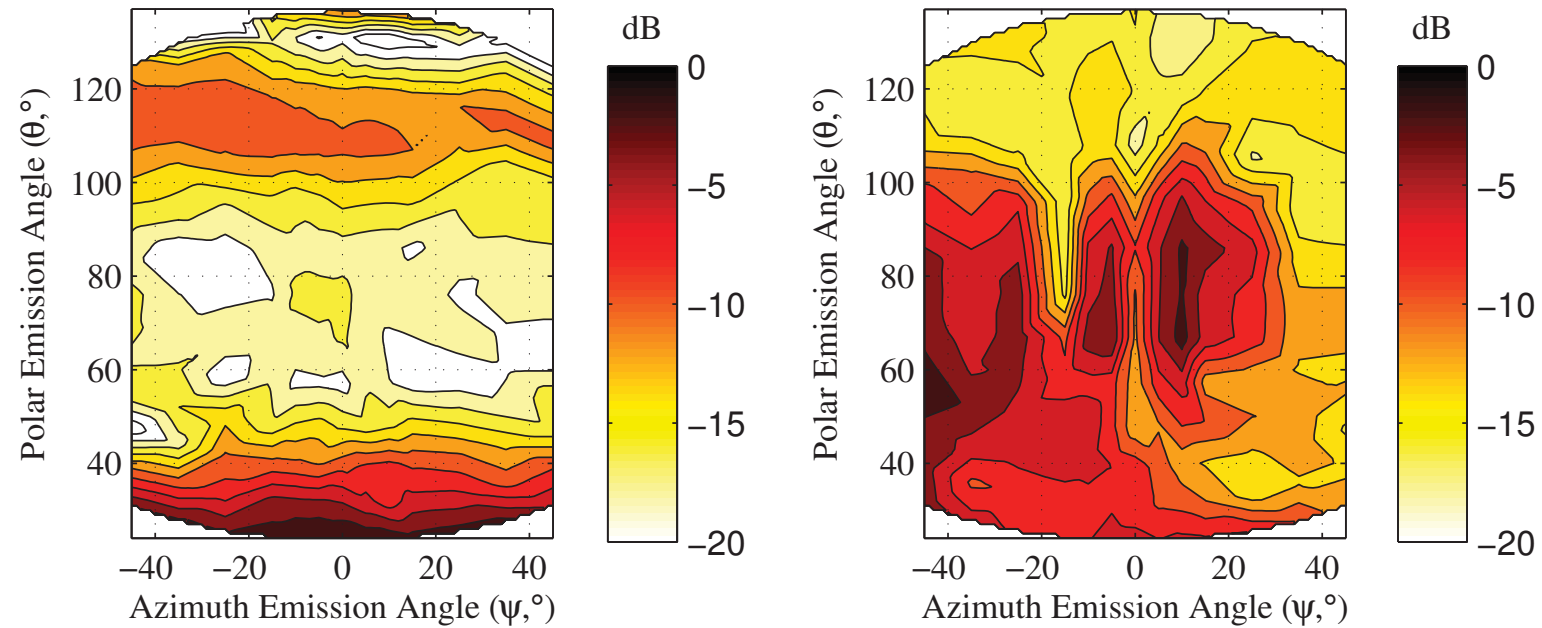

(a) ISI $1 \mathrm{~F}+1 \mathrm{~A}$ tone ( $\mathrm{dB}$ ref peak, contour levels every $2 \mathrm{~dB}$ ). (b) IRS $2 \mathrm{~A}$ tone ( $\mathrm{dB}$ ref peak, contour levels every $2 \mathrm{~dB}$ ).

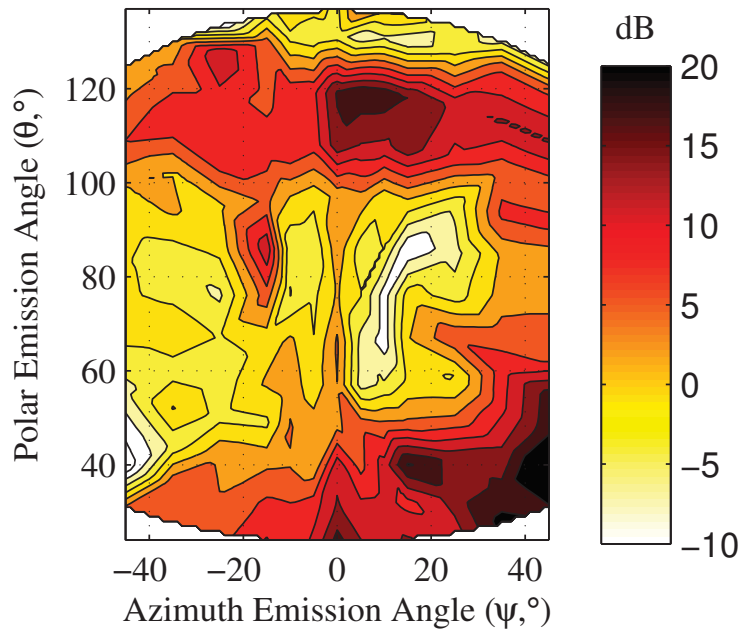

(c) $\Delta d B_{\text {diff }}$ for the $1 \mathrm{~F}+1 \mathrm{~A}$ tone (contour levels every $3 \mathrm{~dB}$ ). The contour range is extended from previous ranges for this plot to capture the full range of the data.

Figure 17. Case 2 directivity plots for the tone matching of ISI $1 \mathrm{~F}+1 \mathrm{~A}$, along with the associated suppression map difference. 


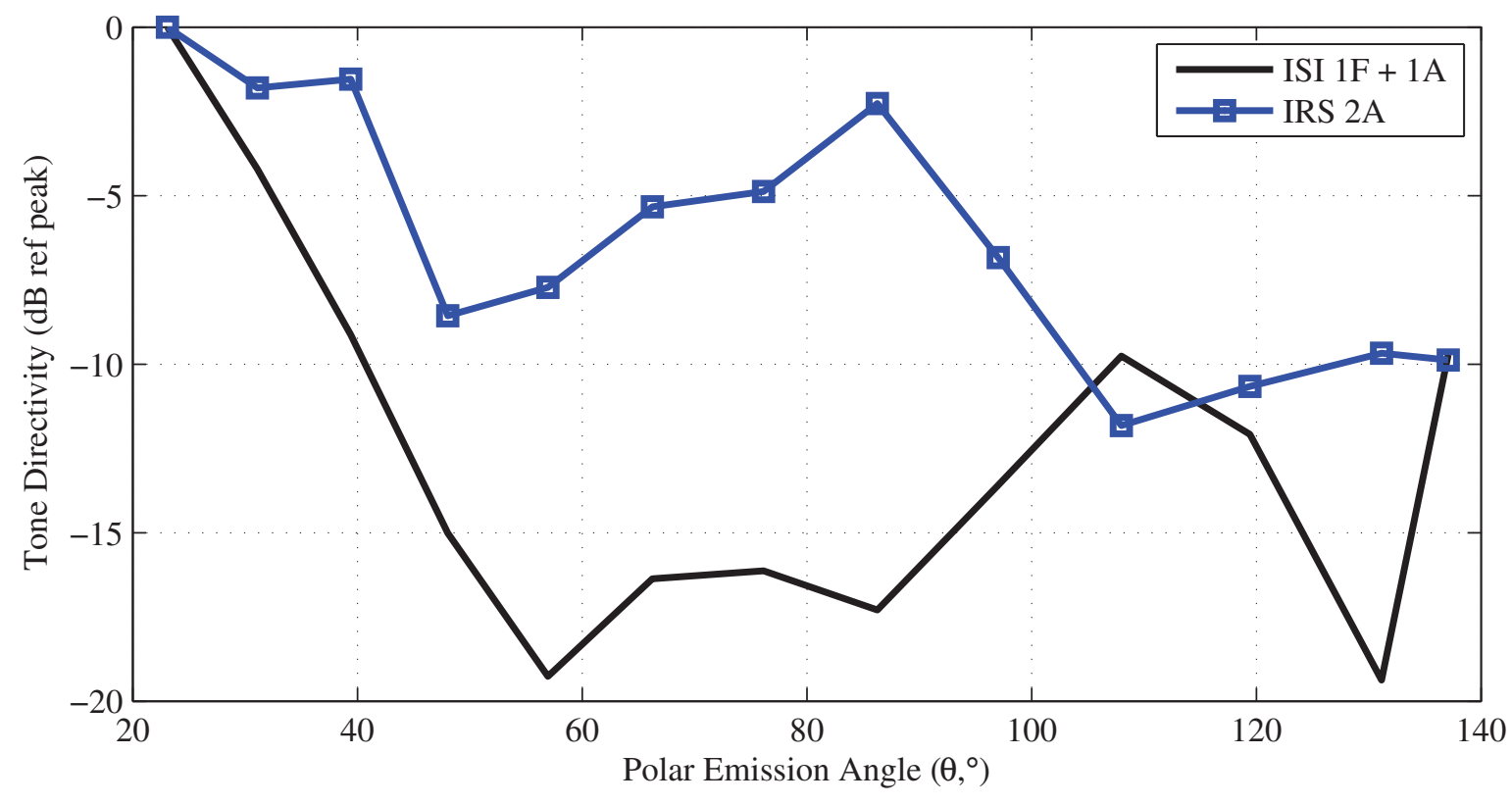

Figure 18. Case $2 \psi=0^{\circ}$ directivity plots for the tone matching of ISI $1 \mathrm{~F}+1 \mathrm{~A}$.

method for these two test cases, tone matching provides additional tools for determining the quality of the mapping of shielding information to a source on a tone-by-tone level. These initial results suggest that the tone matching between data sets can be biased by a limited directivity measurement or directivity shape changes when a simple mean-square error calculation is used. These results also suggest that steep gradients in the difference between directivity patterns may play a role in this mapping.

Based on the two test cases studied here in depth, one moderate and one severe, it appears that both methods approach experimental data in an EPNL calculation as long as the sources have similar frequency content. Both have more difficulty once the frequency content changes, although the differences on an EPNL level are still small for a system assessment. However, the direct difference method offers no mechanism for improvement of the method. The tone matching method contains mechanisms that offer potential for future improvement. For example, alternative weighting schemes or improved error estimates for the directivity fitting might be potential devices to improve the match of autospectral maps. Consideration could also be given towards how to apply the shielding information when there is a small shift in source directivity (which leads to a steep gradient in the difference between directivity patterns). Additional information such as cross-spectral relationships or time domain data could be leveraged, when available.

Overall, the tone matching method has the potential to include more physical aspects and should produce higher fidelity results than the direct difference method. This method is well suited to integration into a system noise assessment process. Initial application of the method provides a road map for the maturation of the technique for more general use. To aid in further development, future open rotor Propulsion Airframe Aeroacoustic experiments should be designed to incorporate test cases tailored to benchmark shielding application methods.

\section{Acknowledgments}

The authors thank the NASA Environmentally Responsible Aviation Project, Dr. Fay Collier, Project Manager, for funding this research. 


\section{References}

${ }^{1}$ Collier, F. S., "Environmentally Responsible Aviation (ERA) Project," presentation at the Third NASA Fundamental Aeronautics Program Annual Meeting, September 29 - October 12009.

${ }^{2}$ Liebeck, R. H., "Design of the Blended-Wing-Body Subsonic Transport," 40th AIAA Aerospace Sciences Meeting 86 Exhibit, AIAA-2002-0002, Reno, NV, January 2002.

${ }^{3}$ Pitera, D. M., DeHann, M., Brown, D., Kawai, R. T., Hollowell, S., Camacho, P., Bruns, D., and Rawden, B. K., "Hybrid Wing Body Concept Development with Open Rotor Engine Integration," Tech. Rep. NASA CR-2011-217303, November 2011.

${ }^{4}$ Hoff, G. et al., "Experimental Performance and Acoustic Investigation of Modern, Counterrotating Blade Concepts," Tech. Rep. NASA-CR-185158, 1990.

${ }^{5}$ Bowles, M. D., "The 'Apollo' of Aeronautics, NASA's Aircraft Energy Efficiency Program," Tech. Rep. NASA SP-2009574,2010 .

${ }^{6}$ Guynn, M. D., Berton, J. J., Haller, W. J., Hendricks, E. S., and Tong, M. T., "Performance and Environmental Assessment of an Advanced Aircraft with Open Rotor Propulsion," Tech. Rep. NASA TM-2012-217772, 2012.

${ }^{7}$ Lopes, L. V. and Burley, C. L., "Design of the Next Generation Aircraft Noise Prediction Program: ANOPP2," 17th AIAA/CEAS Aeroacoustics Conference, AIAA-2011-2854, Portland, OR, June 2011.

${ }^{8}$ Thomas, R. H., Burley, C. L., and Olson, E. D., "Hybrid Wing Body Aircraft System Noise Assessment with Propulsion Airframe Aeroacoustic Experiments," International Journal of Aeroacoustics, Vol. 11, No. 3+4, 2012.

${ }^{9}$ Guo, Y., Burley, C. L., and Thomas, R. H., "On Noise Assessment for Blended Wing Body Aircraft," 52nd AIAA Aerospace Sciences Meeting (accepted for publication), National Harbor, MD, January 2014.

${ }^{10}$ Czech, M. J. and Thomas, R. H., "Open Rotor Aeroacoustic Installation Effects for Conventional and Unconventional Airframes," 19th AIAA/CEAS Aeroacoustics Conference, AIAA-2013-2185, Berlin, Germany, June 2013.

${ }^{11}$ Guo, Y., Czech, M. J., and Thomas, R. H., "Open Rotor Noise Shielding by Blended-Wing-Body Aircraft," 52nd AIAA Aerospace Sciences Meeting (accepted for publication), National Harbor, MD, January 2014.

${ }^{12}$ Guo, Y. and Thomas, R. H., "System Noise Assessment of Blended-Wing-Body Aircraft with Open Rotor Propulsion," 52nd AIAA Aerospace Sciences Meeting (accepted for publication), National Harbor, MD, January 2014.

${ }^{13}$ Thomas, R. H., Burley, C. L., Lopes, L. V., Bahr, C. J., Gern, F. H., and Van Zante, D. E., "System Noise Assessment and the Potential for a Low Noise Hybrid Wing Body Aircraft with Open Rotor Propulsion," 52nd AIAA Aerospace Sciences Meeting (accepted for publication), National Harbor, MD, January 2014.

${ }^{14}$ McAlpine, A., Powles, C. J., and Tester, B. J., "A Weak-Scattering Model for Turbine-Tone Haystacking," Journal of Sound and Vibration, Vol. 332, No. 16, August 2013, pp. 3806-3831.

${ }^{15}$ Van Zante, D. E., Gazzaniga, J., Eliott, D., and Woodward, R. P., "An Open Rotor Test Case: F31/A31 Historical Baseline Blade Set," ISABE-2011-1310, Gothenburg, Sweden, September 2011.

${ }^{16}$ Whitfield, C. E., Mani, R., and Gliebe, P. R., "High Speed Turboprop Aeroacoustic Study (Counterrotation)," Tech. Rep. NASA-CR-185241, 1990.

${ }^{17}$ Rizzi, S. A., Aumann, A. R., Lopes, L. V., and Burley, C. L., "Auralization of Hybrid Wing Body Aircraft Flyover Noise from System Noise Predictions," 51st AIAA Aerospace Sciences Meetiing 85 Exhibit, AIAA-2013-0542, January 2013. 